\title{
Synthesis of an Addition-Crosslinkable, Silicon-Modified Polyolefin via Reactive Extrusion Monitored by In-Line Raman Spectroscopy
}

\author{
Steffen Ulitzsch ${ }^{1,2}\left(\mathbb{D}\right.$, Tim Bäuerle ${ }^{1,2}$, Mona Stefanakis ${ }^{1,2} \mathbb{D}$, Marc Brecht ${ }^{1,2,3} \mathbb{D}$, Thomas Chassé ${ }^{3}$, \\ Günter Lorenz ${ }^{1,2}$ (D) and Andreas Kandelbauer 1,2,*(D) \\ 1 Center for Process Analysis \& Technology (PA\&T), School of Applied Chemistry, Reutlingen University, \\ Alteburgstrasse 150, 72762 Reutlingen, Germany; steffen.ulitzsch@Reutlingen-University.de (S.U.); \\ tim.baeuerle@reutlingen-university.de (T.B.); mona.stefanakis@reutlingen-university.de (M.S.); \\ marc.brecht@reutlingen-university.de (M.B.); guenter.lorenz@reutlingen-university.de (G.L.) \\ 2 Reutlingen Research Institute (RRI), Reutlingen University, Alteburgstrasse 150, 72762 Reutlingen, Germany \\ 3 Institute of Physical and Theoretical Chemistry, University of Tübingen, Auf der Morgenstelle 18, \\ 72076 Tübingen, Germany; Thomas.Chasse@uni-tuebingen.de \\ * Correspondence: andreas.kandelbauer@reutlingen-university.de; Tel.: +49-7121-271-2009
}

Citation: Ulitzsch, S.; Bäuerle, T.; Stefanakis, M.; Brecht, M.; Chassé, T.; Lorenz, G.; Kandelbauer, A. Synthesis of an Addition-Crosslinkable,

Silicon-Modified Polyolefin via Reactive Extrusion Monitored by In-Line Raman Spectroscopy. Polymers 2021, 13, 1246. https://doi.org/10.3390/ polym13081246

Academic Editor: Dimitrios

G. Papageorgiou

Received: 29 March 2021

Accepted: 6 April 2021

Published: 12 April 2021

Publisher's Note: MDPI stays neutral with regard to jurisdictional claims in published maps and institutional affiliations.

Copyright: (C) 2021 by the authors Licensee MDPI, Basel, Switzerland. This article is an open access article distributed under the terms and conditions of the Creative Commons Attribution (CC BY) license (https:// creativecommons.org/licenses/by/ $4.0 /)$.
Abstract: We present the modification of ethylene-propylene rubber (EPM) with vinyltetramethydisiloxane (VTMDS) via reactive extrusion to create a new silicone-based material with the potential for high-performance applications in the automotive, industrial and biomedical sectors. The radical-initiated modification is achieved with a peroxide catalyst starting the grafting reaction. The preparation process of the VTMDS-grafted EPM was systematically investigated using process analytical technology (in-line Raman spectroscopy) and the statistical design of experiments (DoE). By applying an orthogonal factorial array based on a face-centered central composite experimental design, the identification, quantification and mathematical modeling of the effects of the process factors on the grafting result were undertaken. Based on response surface models, process windows were defined that yield high grafting degrees and good grafting efficiency in terms of grafting agent utilization. To control the grafting process in terms of grafting degree and grafting efficiency, the chemical changes taking place during the modification procedure in the extruder were observed in real-time using a spectroscopic in-line Raman probe which was directly inserted into the extruder. Successful grafting of the EPM was validated in the final product by ${ }^{1} \mathrm{H}-\mathrm{NMR}$ and FTIR spectroscopy.

Keywords: reactive extrusion; silane modification; hydride modification; vinyltetramethyldi-siloxane (VTMDS); response surface analysis; ethylene-propylene copolymer (EPM); grafting; process analytical technology (PAT); in-line spectroscopy; in situ analysis

\section{Introduction}

High-performance polymers receive considerable attention due to their special property profiles, enabling their usage in highly demanding application fields. Although standard thermoplastic materials like polyolefins are as such often insufficient, their performance can be enhanced by crosslinking them using various physical and chemical methods [1]. By grafting organosilanes onto them, an addition-crosslinkable system is produced that allows the formation of covalent crosslinkages via the grafted silane functionalities. Prominent examples include the vinyl trimethoxysilane (VTMS) grafted polyolefines ethylene propylene (EPM-g-VTMS) [2] and ethylene octene (EOC-g-VTMS) [3,4], co-polymers that combine the performance characteristics of poly-olefinic systems with silicon-containing polymers.

In the crosslinked state, high-performance synthetic elastomers are obtained that can be used, for instance, as sealants in the automotive and construction industries due to their extraordinary chemical stability, mechanical performance and durability. These properties 
make them also suitable as membrane materials for polymer electrolyte membrane (PEM) fuel cells [5-10]. Due to their chemical inertness and inherent biocompatibility, such elastomers may also be well suited as implant materials for biomedical applications, among many other applications [11-13]. Silicone rubbers are, for example, well known as breast implant materials [14].

In this work, a new addition-crosslinkable base-polymer with the potential for highperformance applications as synthetic rubber was produced and the possibility for in-line process control via in situ Raman spectroscopy was demonstrated. EPM was grafted with vinyltetramethyldisiloxane (VTMDS) via a reactive extrusion process to yield EPMg-VTMDS. Before grafting, VTMDS was freshly prepared and subsequently purified via distillation.

The reactive extrusion process was monitored in-line by means of in situ Raman spectroscopy via a probe integrated in the extrusion line. Multivariate calibration of the Raman spectra with chemical properties was carried out based on principal component analysis (PCA) and partial least squares regression (PLS-R). With in-line Raman/PCA it was possible to quantify the amounts of grafting monomer during reactive extrusion. The grafting degree was determined using ${ }^{1} \mathrm{H}-\mathrm{NMR}$ spectroscopy. These data were used to calibrate the in-line Raman spectra to build a quantitative PLS-R model for predicting the grafting degree based on Raman signals. Thus, it is shown that both raw material consumption and formation of the grafted material can be monitored using in-line Raman spectroscopic probes directly in the process.

\section{Materials and Methods}

\subsection{Chemicals}

The liquid ethylene-propylene copolymer (EPM; Trilene ${ }^{\circledR} \mathrm{CP}-80$ ) was purchased from Lion Elastomers, LLC (Geismar, Los Angeles, CA, USA). The peroxide initiator 2,5-dimethyl-2,5-di(tert-butylperoxy)hexane (DTBPH; Luperox ${ }^{\circledR} 101$ ) was supplied from Arkema (Colombes, France). Tetramethyldisiloxane (M1) and divinyltetramethyldisiloxane (M2) were kindly donated by CHT Germany GmbH (Tübingen, Germany). Vinyltetramethyldisiloxane (VTMDS, M3) was synthesized and purified via fractional distillation prior to the grafting reaction. Deuterated chloroform (99.8\%) was purchased from Deutero $\mathrm{GmbH}$ (Kastellaun, Germany) and dried over $3 \AA$ molecular sieves. Benzyl benzoate, trifluoromethanesulfonic acid and sodium hydrogen carbonate were received from SigmaAldrich Chemie GmbH (Taufkirchen, Germany).

\subsection{Synthesis of Vinyltetramethyldisiloxane (VTMDS, M3)}

The synthesis of vinyltetramethyldisiloxane (VTMDS, M3) was performed in a 5-L round-bottom flask. The equilibration reaction is shown in Figure 1. For the reaction, $1675.23 \mathrm{~g}$ tetramethyldisiloxane (M1, $134.32 \mathrm{~g} / \mathrm{mol}$ ) and $2324.77 \mathrm{~g}$ divinyltetramethyldisiloxane $(\mathrm{M} 2,186.40 \mathrm{~g} / \mathrm{mol})$ were combined in a 1:1 molar ratio, then $4.00 \mathrm{~g}$ acid was added and the mixture was stirred. At-line monitoring via infrared spectroscopy showed rapid equilibration within less than $1 \mathrm{~min}$ at a starting temperature of $25^{\circ} \mathrm{C}$ without external heating. The equilibrium reaction was stopped by removing the catalyst. For this purpose, $40 \mathrm{~g}$ of each water and sodium hydrogen carbonate were added until the solution was neutral to slightly alkaline. The phases were separated via a separating funnel. VTMDS was purified by fractional distillation before further use.

M1<smiles>C[SiH2]O[SiH](C)C</smiles>

$\mathrm{M} 2$<smiles>C=C[Si](C)(C)O[Si](C)(C)C=C</smiles>

M3

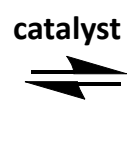<smiles>C=C[Si](C)(C)O[SiH](C)C</smiles>

Figure 1. Synthesis of vinyltetramethyldisiloxane (M3; VTMDS) by equilibration of tetramethyldisiloxane (M1) and divinyltetramethyldisiloxane (M2) with trifluoromethanesulfonic acid as a catalyst. 


\subsection{Silane Grafting by Reactive Extrusion}

The peroxide-initiated grafting reaction of VTMDS onto EPM was done with a corotating twin-screw extruder (Coperion ZSK 18, Stuttgart, Germany) with a screw diameter of $18 \mathrm{~mm}$ and a length/diameter $(\mathrm{L} / \mathrm{D})$ ratio of 48 . The chemical reaction is shown in Figure 2. 2,5-dimethyl-2,5-di(tert-butylperoxy)hexane (DTBPH) was used as the peroxide initiator.

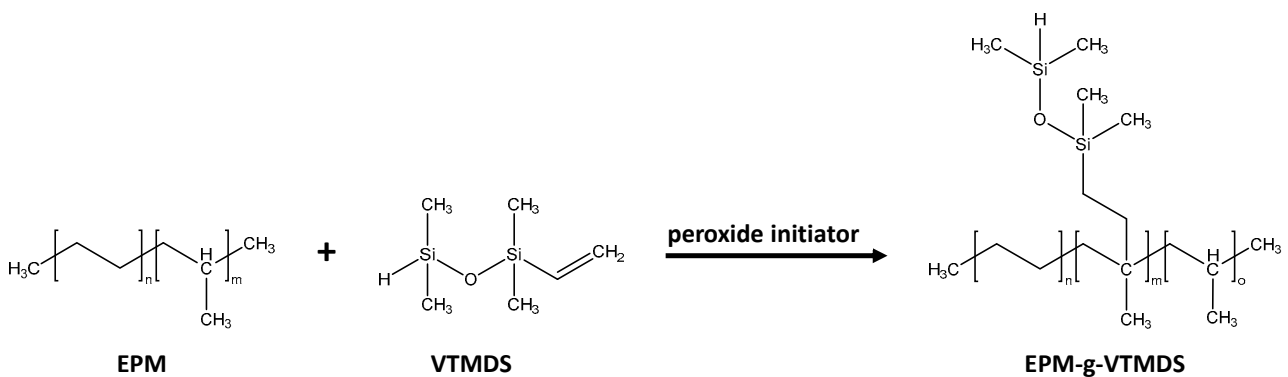

Figure 2. Peroxide-initiated grafting reaction of VTMDS onto ethylene-propylene rubber (EPM).

Figure 3 shows schematically the reactive extrusion setup with the feeding arrangement and Raman-probe. The liquid EPM was fed using a heated melt pump (Beinlich Pumpen $\mathrm{GmbH}$, Gevelsberg, Germany). Argon was used as a protective gas and was also added at the feeding zone (FZ). At position 1, VTMDS and DTBPH were fed into the extruder via syringe pumps. Six temperature zones and the feeding zone (FZ) were heated and controlled separately. At position 7 the Raman-probe was inserted. This extruder segment was not heated.

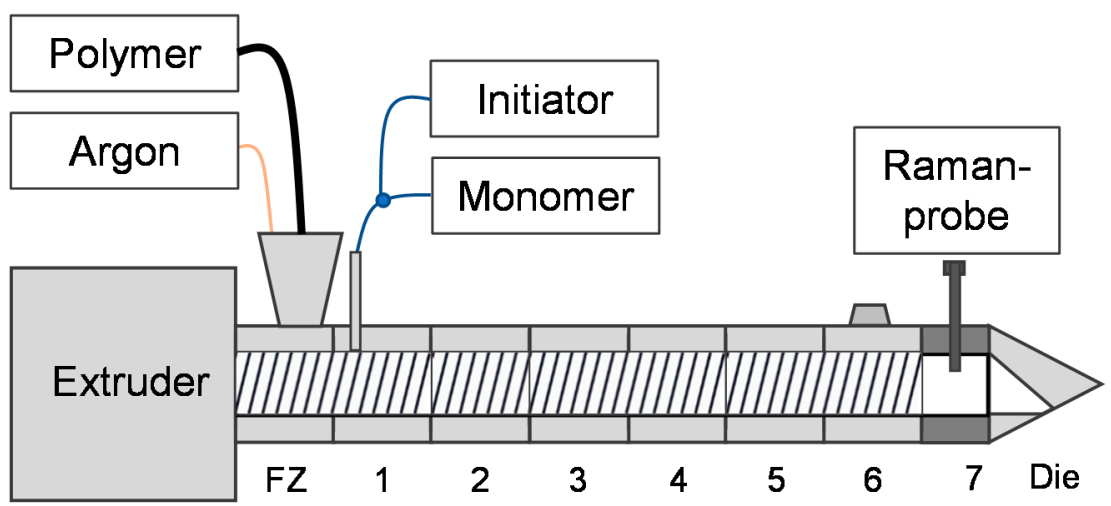

Figure 3. Schematic reactive extrusion setup with feeding arrangement and Raman in situ probe.

The factor-level settings were adjusted to the factor-level combinations as required by the face-centered experimental design (FCD). The in-situ Raman spectroscopic probe placed slightly before the extruder die was used to indicate when the continuous process had stabilized after each change in factor-level settings. This guaranteed that the analyzed material samples adequately reflected the composition at a certain set of factor-level combinations. To ensure the quantitative removal of excess initiator and VTMDS residues, the material samples were placed in a vacuum-drying oven at $80^{\circ} \mathrm{C}$ and dried under an argon stream for $24 \mathrm{~h}$ prior to further analysis.

\subsection{Design of Experiments}

A face-centered experimental design (FCD) with three varied factors was performed to determine the grafting degree and grafting efficiency. The factors studied were VTMDS feed rate (factor A), DTBPH feed rate (factor B) and relative temperature increase (factor C). The values used are listed in Table 1 . The molar ratio between the peroxide initiator 
and grafting monomer was varied from 1:6 to 1:100. The EPM polymer feed was set at $1300 \mathrm{~g} / \mathrm{h}$ : this value ensured the best possible extruder loading and feeding. All factor settings were selected to obtain the feasible limits of reactive extrusion and were determined by preliminary experiments.

Table 1. Factors studied and factor levels used in the face-centered experimental design (FCD).

\begin{tabular}{cccccc}
\hline \multirow{2}{*}{ Factor } & Name & Unit & $\begin{array}{c}\text { Low-Setting } \\
\mathbf{( - 1 )}\end{array}$ & $\begin{array}{c}\text { Centerpoint } \\
\mathbf{( 0 )}\end{array}$ & $\begin{array}{c}\text { High-Setting } \\
\mathbf{( + 1 )}\end{array}$ \\
\hline $\mathrm{A}$ & VTMDS feed & $\mathrm{mol} / \mathrm{h}$ & 0.1 & 0.2 & 0.3 \\
$\mathrm{~B}$ & $\begin{array}{l}\text { DTBPH feed } \\
\text { temperature }\end{array}$ & $\mathrm{mol} / \mathrm{h}$ & 0.003 & 0.010 & 0.017 \\
$\mathrm{C}$ & & & & \\
\hline
\end{tabular}

The detailed settings for the heating segments in the extruder, depending on the respective FCD settings, are given in Table 2.

Table 2. Temperature levels employed in the various segments of the extruder to achieve the desired temperature profiles as required by the FCD.

\begin{tabular}{|c|c|c|c|c|c|c|c|c|}
\hline Setting & $\begin{array}{l}\text { Temperature } \\
\text { Increase }\end{array}$ & Unit & $\begin{array}{c}\text { Segment } \\
1\end{array}$ & $\begin{array}{c}\text { Segment } \\
2\end{array}$ & $\begin{array}{c}\text { Segment } \\
3\end{array}$ & $\begin{array}{c}\text { Segment } \\
4\end{array}$ & $\begin{array}{c}\text { Segment } \\
5\end{array}$ & $\begin{array}{c}\text { Segment } \\
6\end{array}$ \\
\hline$(-1)$ & 0 & ${ }^{\circ} \mathrm{C}$ & 80 & 100 & 130 & 160 & 180 & 180 \\
\hline$(0)$ & 10 & ${ }^{\circ} \mathrm{C}$ & 100 & 120 & 150 & 180 & 200 & 200 \\
\hline$(+1)$ & 20 & ${ }^{\circ} \mathrm{C}$ & 120 & 140 & 170 & 200 & 220 & 220 \\
\hline
\end{tabular}

For planning and analyzing the experiments, the computer program Design Expert (Version: 11.1.2.0 and 12.0.12.0, Stat-Ease, Inc., Minneapolis, MN, USA) was used. To determine the relevant factors and factor interactions, an analysis of variance (ANOVA) was calculated. Only statistically significant effect terms were used to build the response surface models. As a criterion for statistical significance, a significance level of $5 \%$ ( $p$-value of $<0.05$ ) was used.

\subsection{Multivariate Data Analysis}

Multivariate data analysis (MVA) was performed with "The Unscrambler X 10.5" software (Camo Analytics, Oslo, Norway). All in-line Raman spectra were pre-processed using the Savitzky-Golay 1st (smoothed) derivative (symmetric 21 points, 2nd polynomial order).

The principal component analysis (PCA) used to determine the proportion of the VTMDS feed was calculated with mean centering, cross validation (20 random segments) and the Nonlinear Iterative Partial Least Squares (NIPALS)-algorithm. Model outliers were identified in the influence plot of Hotelling's $\mathrm{T}^{2}$ values versus F-residuals (outlier limits $5 \%$ each). The wavenumbers ranged from $1800-300 \mathrm{~cm}^{-1}$ obtained with all 19 sample sets was used for the model.

Partial least squares regression (PLS-R) for prediction of the in-line grafting degree was performed for four factors using mean centering, cross validation (random 20 segments) and the kernel algorithm. All 19 sample sets were divided into calibration set samples (sets number $1-8,10,12-19)$ to develop the PLS-R model and the external validation samples (sets number 9 and 11) to validate the PLS-R model; here, the spectral range $900-300 \mathrm{~cm}^{-1}$ was used.

\subsection{Differential Scanning Calorimetry (DSC) for Boiling Point Determination}

All DSC measurements were performed on a DSC 204 F1 Phoenix from Netzsch (Selb, Germany). Thirteen- to fifteen-milligram samples were weighed into aluminum DSC crucibles (Concavus ${ }^{\circledR}$, Netzsch, Selb, Germany) and covered with a pierced lid. The temperature interval ranged from $-10{ }^{\circ} \mathrm{C}$ to $200{ }^{\circ} \mathrm{C}$; the heating rate was $15.0 \mathrm{~K} / \mathrm{min}$. The 
measurements were performed with a temperature and heat flow calibration. Nitrogen was used as a purge gas with a gas flow of $40 \mathrm{~mL} / \mathrm{min}$ and as a protective gas with a gas flow of $60 \mathrm{~mL} / \mathrm{min}$. Data analysis was done using Netzsch Proteus-Thermal Analysis-software version 7.1.0.

\subsection{Attenuated Total Reflection Fourier Transform Infrared Spectroscopy (ATR-FTIR) for Distillation Monitoring}

Attenuated total reflection Fourier transform infrared spectroscopy (ATR-FTIR) was used for monitoring the distillation (PerkinElmer Inc., Waltham, MA, USA). Spectra were collected in the wavelength range from $4000-600 \mathrm{~cm}^{-1}$. For each single spectrum, 16 scans were accumulated.

\subsection{Raman Spectroscopy for In-Line Monitoring, Process Control and Off-Line Spectra}

A modified Alpha300 SR (WITec GmbH, Ulm, Germany) as described in [14] was used for the Raman spectroscopic off-line measurements using a $20 \times$ objective (Zeiss, EC Epiplan $20 \times / 0.4$ M27); excitation was at $532 \mathrm{~nm}$. The spectra were acquired with integration time $1 \mathrm{~s}$ and 10 accumulations.

An extruder-compatible immersion probe with a flat sapphire window (Dynisco Inc., Franklin, MA 02038, USA) connected to a spectrometer (RXN1, Kaiser Optical Systems, Ann Arbor, MI 48104, USA) was used for the in-line Raman measurements. The spectra were acquired with an exposure time of $10 \mathrm{~s}$, two accumulations and a cosmic ray removal unit.

\subsection{Nuclear Magnetic Resonance Spectroscopy}

The equilibration synthesis and grafting products were characterized by proton nuclear magnetic resonance spectroscopy $\left({ }^{1} \mathrm{H}-\mathrm{NMR}\right)$ measurements. Approximately $25 \mathrm{mg}$ of sample and an additional reference for determination of the grafting degree were weighed into a sampling tube and dissolved in $1.0 \mathrm{~mL}$ deuterated chloroform $\left(\mathrm{CDCl}_{3}\right)$. The measurements were performed on a Bruker AvanceTM III spectrometer (Bruker BioSpin GmbH, Rheinstetten, Karlsruhe, Germany) with a resonance frequency of $400.13 \mathrm{MHz}$, an acquisition time of $4.089 \mathrm{~s}$, a relaxation delay between pulses of $1 \mathrm{~s}$, a pulse width of $14 \mu \mathrm{s}$ and a temperature of $298 \mathrm{~K}$.

The NMR spectra processing and analysis was done with the software package MestreNova (Version: 14.0.1-23559, Mestrelab Research, Santiago de Compostela, Spain). Phase correction and baseline correction were performed and all spectra were referenced to $\mathrm{CDCl}_{3}$ at $7.26 \mathrm{ppm}$.

\subsection{Calculation of Grafting Degree and Grafting Efficiency}

Determination of grafting degree and grafting efficiency was performed in an analogous way as described in previous studies on grafting silane coupling agents onto ethylene propylene (EPM) and ethylene-octene copolymer (EOC) polyolefins [2,4]. The grafting degree as a weight percentage ( $w t \%)$ was calculated according to Equation (1) [2]. Integration areas (I) of reference proton shifts of the reference standards (R) at $5.37 \mathrm{ppm}$ and the grafting product (S) at $4.69 \mathrm{ppm}$ were used. $\mathrm{N}$ is the number of protons of the hydride group, $\mathrm{m}$ the weighed mass, $\mathrm{M}$ the molar mass and $\mathrm{P}$ the purity of the benzyl benzoate reference standard [2].

$$
\text { VTMDS grafting degree }\left(\mathrm{wt}^{\mathrm{o}} \mathrm{o}\right)=\frac{I(S)}{I(R)} \times \frac{N(R)}{N(S)} \times \frac{m(S)}{m(R)} \times \frac{M(S)}{M(R)} \times P(\mathrm{R}) \times 100 \%
$$

Grafting efficiency in wt\% was calculated using Equation (2). For this, the measured VTMDS grafting degree was divided by the grafting degree theoretically expected under the assumption of $100 \%$ conversion [2,4].

$$
\text { VTMDS grafting efficiency }(\%)=\frac{\text { measured grafting degree VTMDS }}{\text { theoretical grafting degree VTMDS }} \times 100 \%
$$




\section{Results and Discussion}

\subsection{Vinyltetramethyldisiloxane (VTMDS) as Grafting Monomer for Reactive Extrusion}

The ${ }^{1} \mathrm{H}-\mathrm{NMR}$ spectra of the equilibration reaction are shown in Figure 4. Tetramethyldisiloxane (M1), divinyltetramethyldisiloxane (M2) and vinyltetramethyldisiloxane (M3; VTMDS) are the pure substances and EQ is the unpurified reaction product. In EQ, all single substances are present in a molar ratio of 1:1:1. At $7.26 \mathrm{ppm}$ the $\mathrm{CDCl}_{3}$ peak of the solvent can be observed, and at $1.56 \mathrm{ppm}$ the water peak of the water which diffused into the sample due to air humidity can be seen. $\mathrm{The}_{\mathrm{SiCH}}$ methyl groups are in the range of $0-0.35 \mathrm{ppm}$, the $\mathrm{SiH}$ hydride group at $4.5-4.9 \mathrm{ppm}$ and the vinyl groups in the range of 5.55-6.3 ppm.

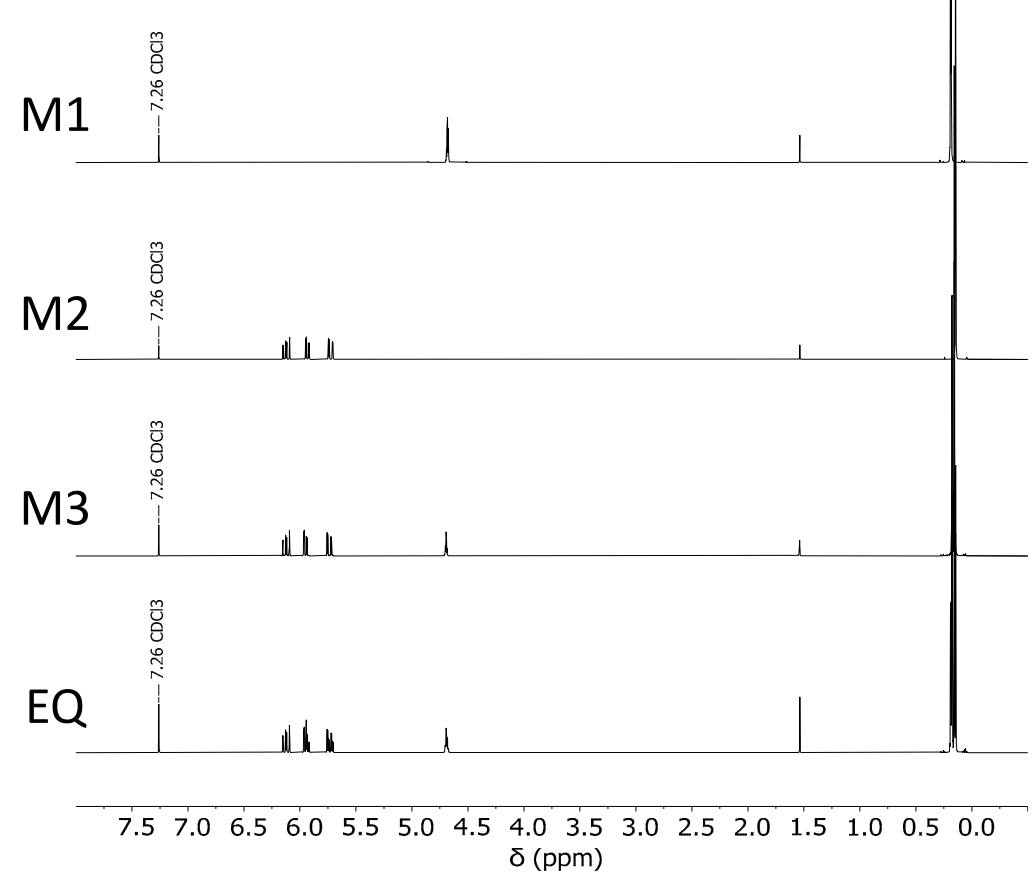

Figure 4. ${ }^{1} \mathrm{H}-\mathrm{NMR}$ spectra of tetramethyldisiloxane (M1), divinyltetramethyldisiloxane (M2), vinyltetramethyldisiloxane (M3; VTMDS) and the equilibration reaction (EQ).

To be able to separate the substances by means of fractional distillation, the boiling points of all three compounds were determined using differential scanning calorimetry (DSC). For this purpose, DSC curves of the three pure substances were measured and the boiling points were determined over the onset, as shown in Figure 5. The following boiling points were determined: $\mathrm{M} 1=72{ }^{\circ} \mathrm{C}, \mathrm{M} 2=142{ }^{\circ} \mathrm{C}$ and $\mathrm{M} 3=109^{\circ} \mathrm{C}$. The boiling point determination for $\mathrm{M} 3$ was the most relevant as there were no standardized values available in the scientific literature for this. Due to the boiling point differences, distillation was performed without a vacuum. 


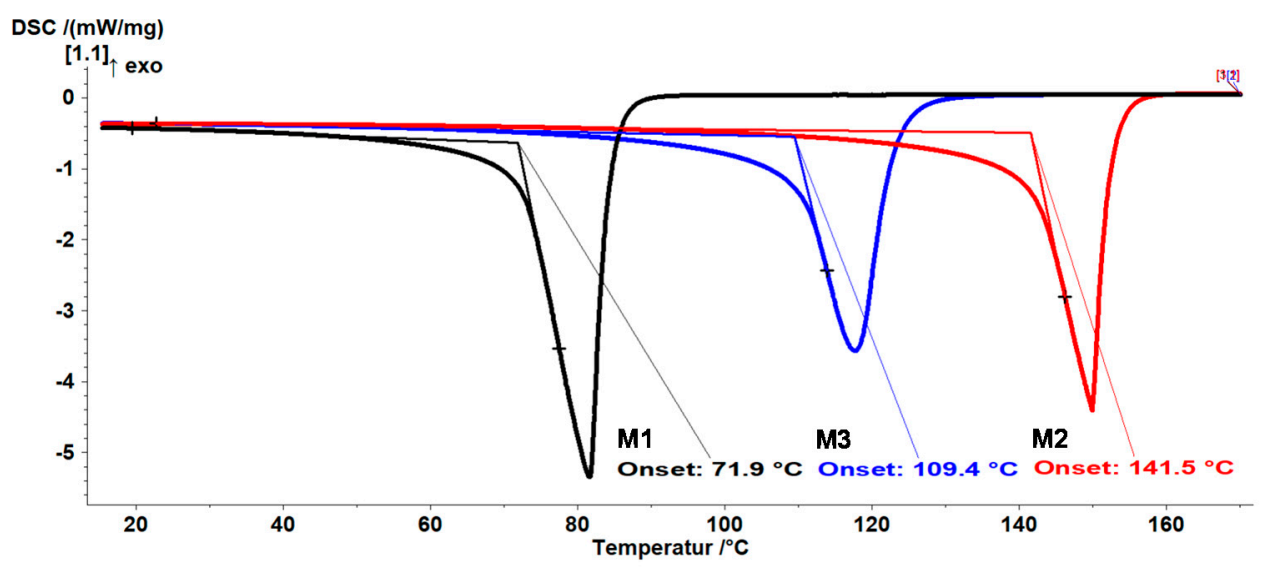

Figure 5. Differential scanning calorimetry (DSC) traces of tetramethyldisiloxane (M1), vinyltetramethyldisiloxane (M3; VTMDS) and divinyltetramethyldisiloxane (M2) used to determine the boiling points for distillation. A heating rate of $15.0 \mathrm{~K} / \mathrm{min}$ was used and nitrogen was used as purge gas with a gas flow of $40 \mathrm{~mL} / \mathrm{min}$ and as protective gas with a gas flow of $60 \mathrm{~mL} / \mathrm{min}$.

At-line monitoring via ATR, FTIR was performed during distillation to achieve the maximum yield and purity of VTMDS (M3). Figure 6a shows the infrared spectra from $1200 \mathrm{~cm}^{-1}$ to $600 \mathrm{~cm}^{-1}$ of the pure substances tetramethyldisiloxane (M1), divinyltetramethyldisiloxane (M2) and vinyltetramethyldisiloxane (M3; VTMDS). Figure $6 \mathrm{~b}$ shows a time series of infrared spectra from the distillation process. M1 is mainly characterized by medium to strong Si-H deformation vibrations at $903 \mathrm{~cm}^{-1}$ and $837 \mathrm{~cm}^{-1}$. At the beginning of the distillation, the $837 \mathrm{~cm}^{-1}$ vibration, denoted by (1), decreases (Figure $6 \mathrm{~b}$ ). The increase of band (2) at $814 \mathrm{~cm}^{-1}$ in the spectrum describes the increase in the Si-H group in the product M3, determined by the $\mathrm{Si}-\mathrm{H}$ deformation vibration. When band (1) was minimal and band (2) was maximal, the extraction of M3 was started $[15,16]$.
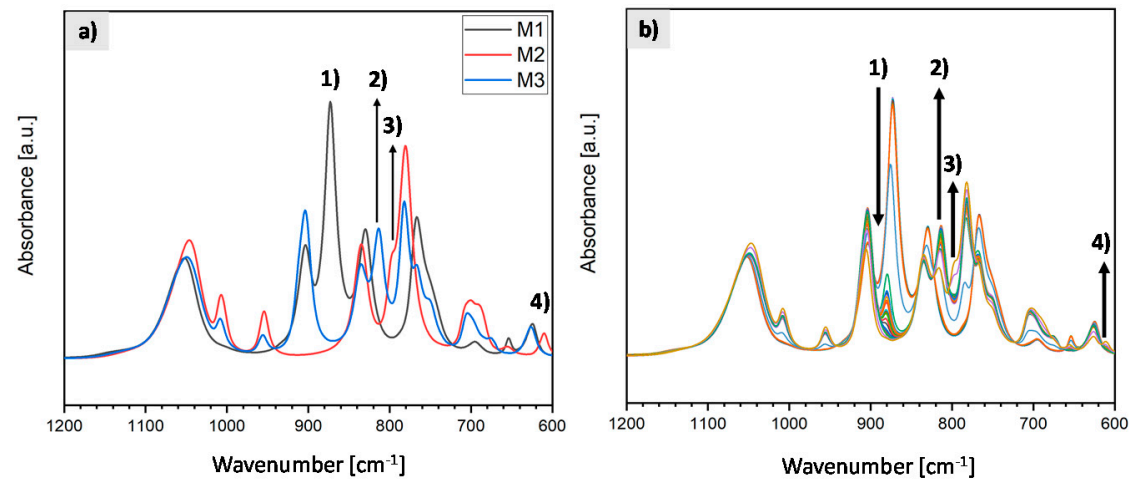

Figure 6. Attenuated total reflection (ATR)-FTIR spectra of (a) tetramethyldisiloxane (M1), divinyltetramethyldisiloxane (M2) and vinyltetramethyldisiloxane (M3; VTMDS) and (b) the distillation process of vinyltetramethyldisiloxane (M3; VTMDS). (1) M1 decreases and upon its complete removal separation of M3 took place. (2) M3 increases. (3) and (4) M2 increases.

The vibrations at $1007 \mathrm{~cm}^{-1}$ (trans $\mathrm{CH}$ wagging) and $954 \mathrm{~cm}^{-1}\left(\mathrm{CH}_{2}\right.$ wagging) are associated with the vinyl group $\mathrm{Si}-\mathrm{CH}=\mathrm{CH}_{2}$ of the reactant $\mathrm{M} 2$. At the end of the distillation, the increase of shoulder (3) and the increase of band (4) are crucial for M2 (Figure 6b). As soon as bands (3) and (4) increase and, thus, more M2 is present again, pure M3 is no longer present and the distillation is ended. Shoulder (3) at $797 \mathrm{~cm}^{-1}$ is caused by the medium to strong $\mathrm{Si}-\mathrm{CH}_{3}$ or $\mathrm{Si}-\mathrm{C}$ rocking vibrations. Band (4) at $610 \mathrm{~cm}^{-1}$ describes the broad symmetric $\mathrm{Si}-\mathrm{O}-\mathrm{Si}$ stretching band for disiloxanes. Both bands are present only in 
M2 at these wavenumbers (see Figure 6a). Minor shifts in the bands during the reaction and distillation process are caused by changes in the overall electric dipole moment of the molecules and their interaction with the surrounding molecules. Due to the progressive reaction and the formation of $\mathrm{M} 3$, which contains both $\mathrm{Si}-\mathrm{H}$ and $\mathrm{Si}-\mathrm{CH}=\mathrm{CH}_{2}$ as functional groups, the net electric dipole moment of $\mathrm{M} 3$ changes, despite the stoichiometric conservation of the $\mathrm{Si}-\mathrm{H}$ and $\mathrm{Si}-\mathrm{CH}=\mathrm{CH}_{2}$ functional groups. As a result, in the basic structure of the molecule $\mathrm{M} 3$, the $\mathrm{Si}-\mathrm{CH}_{3}$ and $\mathrm{Si}-\mathrm{O}-\mathrm{Si}$ vibrations are also affected, and these bands are slightly shifted. Due to the decrease in the concentration of M3 during the course of the reaction and the resulting change in molecular composition, the direction of this shift is reversed $[15,16]$. VTMDS (M3) was further used in the grafting reactions.

\subsection{Structural Characterization of the Reaction Products}

The successful grafting reaction of VTMDS onto EPM, as monitored by ${ }^{1} \mathrm{H}-\mathrm{NMR}$, is shown in Figure 7. Figure 7a shows the EPM polymer. Figure $7 \mathrm{~b}$ shows the grafted product, EPM-g-VTMDS. The relevant ranges are $0-1.8 \mathrm{ppm}$ for the mainly polyolefinic $\mathrm{CH} / \mathrm{CH}_{2} / \mathrm{CH}_{3}$ groups and $-0.25-0.5 \mathrm{ppm}$ for the $\mathrm{Si}-\mathrm{CH}_{2} / \mathrm{Si}-\mathrm{CH}_{3}$ groups. The signal at a chemical shift of $4.69 \mathrm{ppm}$ is characteristic for the $\mathrm{SiH}$ hydride group and indicates successful hydride modification of the polyolefin.

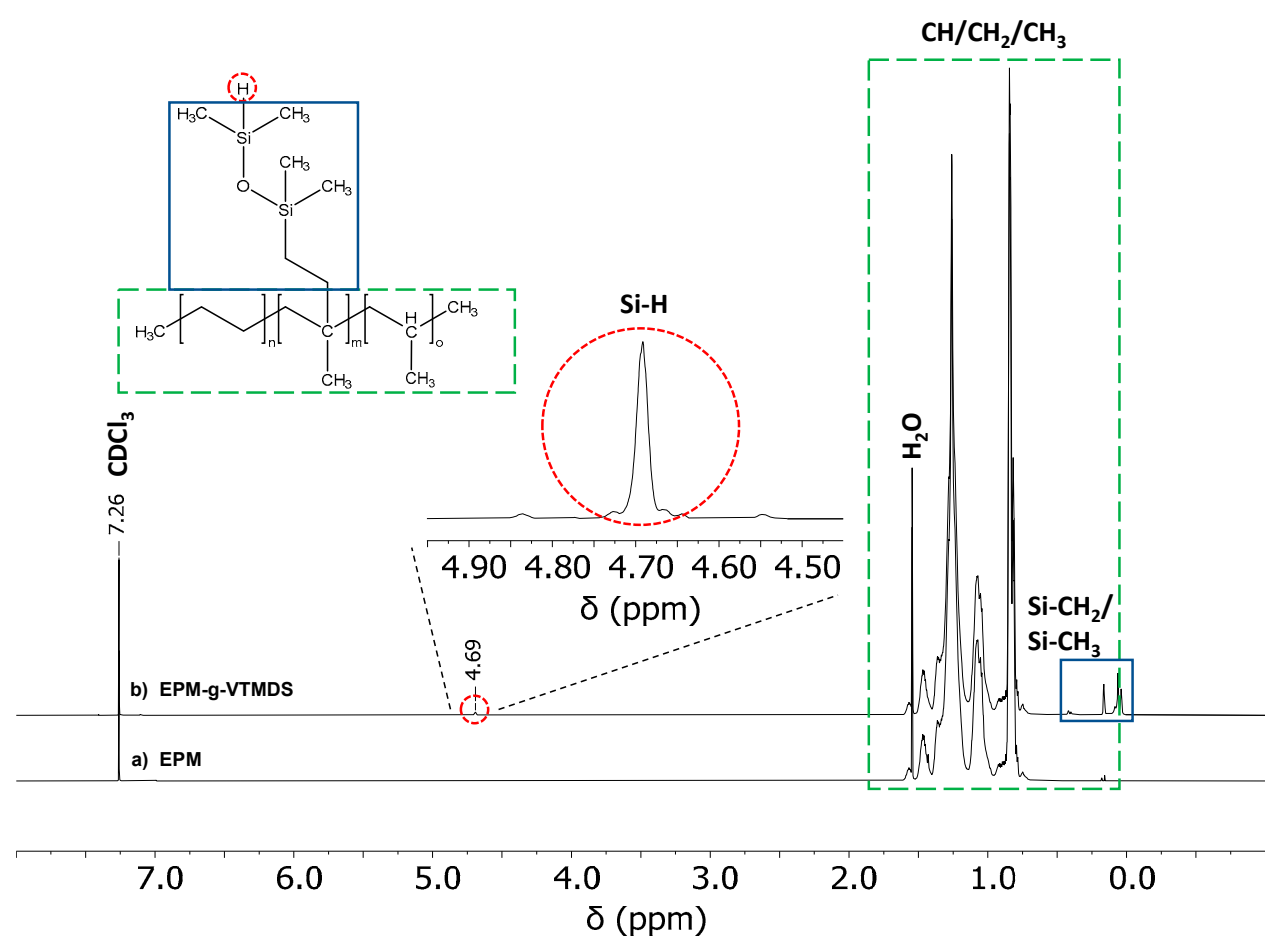

Figure 7. ${ }^{1} \mathrm{H}-\mathrm{NMR}$ spectra of (a) raw unmodified EPM and (b) EPM-g-VTMDS.

\subsection{Quantitative Determination of Grafting Degree and Grafting Efficiency}

The results of the experimental design are summarized in Table 3. The grafting degree was calculated with Equation (1) and the grafting efficiency was calculated using Equation (2). All experiments were performed in one block. The experiments are listed in the actual run order. To determine the experimental error with high accuracy, six center point $(\mathrm{CP})$ experiments at intermediate factor-level settings were performed.

For all experiments the overall range of grafting degrees achieved was between $0.33 \mathrm{wt} \%$ and $1.92 \mathrm{wt} \%$. The grafting efficiency for all experiments was between $16.14 \%$ and $85.03 \%$. This is well within the expected range of grafting degrees observed with similar grafting reactions performed via reactive extrusion in earlier studies [2,4]. All experiments were included in the model building. 
Table 3. Experimental data for response surface analysis of the face-centered experimental design with three-level factor settings for the three factors. The experiments are shown in the randomized order in which the single runs were actually performed.

\begin{tabular}{|c|c|c|c|c|c|c|c|c|}
\hline \multirow{2}{*}{ Serial No. } & \multicolumn{3}{|c|}{ Factor Pattern } & \multicolumn{3}{|c|}{ Independent Variable } & \multicolumn{2}{|c|}{ Response Variable } \\
\hline & A & B & $\mathrm{C}$ & $\begin{array}{c}\text { A: VTMDS } \\
\text { Feed (mol/h) }\end{array}$ & $\begin{array}{c}\text { B: DTBPH } \\
\text { Feed (mol/h) }\end{array}$ & $\begin{array}{c}\text { C: Temp. } \\
\text { Increase (K) }\end{array}$ & $\begin{array}{c}\text { Grafting } \\
\text { Degree (wt } \%)\end{array}$ & $\begin{array}{c}\text { Relative } \\
\text { Grafting (\%) }\end{array}$ \\
\hline 1 & -1 & 1 & -1 & 0.1 & 0.017 & 0 & 0.67 & 68.00 \\
\hline 2 & 1 & 1 & -1 & 0.3 & 0.017 & 0 & 1.43 & 37.21 \\
\hline 3 & 0 & 0 & 0 & 0.2 & 0.010 & 20 & 1.35 & 54.50 \\
\hline 4 & -1 & 0 & 0 & 0.1 & 0.010 & 20 & 0.76 & 77.27 \\
\hline 5 & -1 & -1 & 1 & 0.1 & 0.003 & 40 & 0.46 & 46.12 \\
\hline 6 & -1 & 1 & 1 & 0.1 & 0.017 & 40 & 0.84 & 85.03 \\
\hline 7 & 1 & 1 & 1 & 0.3 & 0.017 & 40 & 1.92 & 50.05 \\
\hline 8 & 0 & 0 & 1 & 0.2 & 0.010 & 40 & 1.22 & 49.36 \\
\hline 9 & 0 & 0 & 0 & 0.2 & 0.010 & 20 & 1.36 & 55.22 \\
\hline 10 & 0 & 0 & 0 & 0.2 & 0.010 & 20 & 1.22 & 49.31 \\
\hline 11 & 0 & 1 & 0 & 0.2 & 0.017 & 20 & 1.39 & 56.40 \\
\hline 12 & 1 & 0 & 0 & 0.3 & 0.010 & 20 & 1.52 & 39.56 \\
\hline 13 & 0 & -1 & 0 & 0.2 & 0.003 & 20 & 0.72 & 28.95 \\
\hline 14 & 0 & 0 & 0 & 0.2 & 0.010 & 20 & 1.22 & 49.56 \\
\hline 15 & 0 & 0 & 0 & 0.2 & 0.010 & 20 & 1.26 & 50.88 \\
\hline 16 & 0 & 0 & -1 & 0.2 & 0.010 & 0 & 0.93 & 37.55 \\
\hline 17 & 1 & -1 & -1 & 0.3 & 0.003 & 0 & 0.62 & 16.14 \\
\hline 18 & -1 & -1 & -1 & 0.1 & 0.003 & 0 & 0.33 & 33.45 \\
\hline 19 & 0 & 0 & 0 & 0.2 & 0.010 & 20 & 1.25 & 50.40 \\
\hline 20 & 1 & -1 & 1 & 0.3 & 0.003 & 40 & 0.83 & 21.70 \\
\hline
\end{tabular}

\subsection{Effect of Process Variables on Grafting Degree}

To determine the effect of the varied process parameters on the grafting degree, ANOVA was performed (Table 4). Six effect terms with a $p$-value less than 0.05 were obtained to build a response surface model containing only statistically significant model terms. The various coefficients of determination calculated for model evaluation indicate that the model fits the data very well $\left(R^{2}=0.9690\right)$, contains an appropriate number of model terms $\left(R^{2}\right.$ adjusted $\left.=0.9546\right)$ and allows good and robust predictions $\left(\mathrm{R}^{2}\right.$ predicted $\left.=0.9114\right)$.

Table 4. ANOVA for response surface analysis of grafting degree.

\begin{tabular}{cccccc}
\hline Source & $\begin{array}{c}\text { Degree of } \\
\text { Freedom }(\mathbf{d f})\end{array}$ & $\begin{array}{c}\text { Sum of } \\
\text { Squares }\end{array}$ & $\begin{array}{c}\text { Mean } \\
\text { Square }\end{array}$ & F-Value & $\boldsymbol{p}$-Value \\
\hline Model & 2.99 & 6 & 0.4984 & 67.65 & $<0.0001$ \\
A-VTMDS feed & 1.06 & 1 & 1.06 & 144.26 & $<0.0001$ \\
B-DTBPH feed & 1.08 & 1 & 1.08 & 146.93 & $<0.0001$ \\
C-temperature increase & 0.1664 & 1 & 0.1664 & 22.59 & 0.0004 \\
AB & 0.174 & 1 & 0.174 & 23.63 & 0.0003 \\
B $^{2}$ & 0.1125 & 1 & 0.1125 & 15.27 & 0.0018 \\
C $^{2}$ & 0.0898 & 1 & 0.0898 & 12.19 & 0.004 \\
Residual & 0.0958 & 13 & 0.0074 & & \\
Lack of Fit & 0.076 & 8 & 0.0095 & 2.41 & 0.174 \\
Pure Error & 0.0197 & 5 & 0.0039 & & - \\
Cor Total & 3.09 & 19 & - & - & - \\
\hline
\end{tabular}

The linear contributions of the factor effects VTMDS feed rate (factor A) and DTBPH feed rate (factor B) on the grafting degree are the most important effects that mainly determine the system behavior. They are both in the same order of magnitude and about three times higher than the linear impact of temperature increase (factor C). In addition, 
changes in the DTBPH feed rate result in non-linear response behavior of the grafting degree, as indicated by the significant non-linear effect term $B^{2}$. The positive values indicate that an increase in factor level leads to a higher grafting degree. VTMDS and DTBPH feed rates are involved in a second-order interaction (the two-factor interaction term $\mathrm{AB}$ ). This means that the effects of changes in VTMDS feed rate depend on the settings of DTBPH feed rate at which the changes in VTMDS feed rate are made, or, in other words, that VTMDS and DTBPH feed rates must be adjusted together in a coordinated manner in order to achieve a desired grafting degree. The temperature increase also induces a non-linear response of the grafting degree. This shows that there is an optimum value for DTBPH feed rate and temperature increase, whereas an increase in VTMDS feed rate always leads to higher grafting degrees. The model equation in terms of coded values summarizes the relative importance of factor effect terms: grafting degree VTMDS $\left(\mathrm{wt}^{\mathrm{t}} \%\right)=1.24+$ $0.3260 \times \mathrm{A}+0.3290 \times \mathrm{B}+0.1290 \times \mathrm{C}+0.1475 \times \mathrm{AB}-0.1875 \times \mathrm{B}^{2}-0.1675 \times \mathrm{C}^{2}$.

The molar ratio between VTMDS monomer and peroxide has no effect on the grafting degree. Specific values for the target response grafting degree can be calculated using the factor effects equation in actual terms: grafting degree VTMDS $(\mathrm{wt} \%)=-0.137224+1.15286 \times$ $\mathrm{A}+81.38776 \times \mathrm{B}+0.023200 \times \mathrm{C}+210.71429 \times \mathrm{AB}-3826.53061 \times \mathrm{B}^{2}-0.000419 \times \mathrm{C}^{2}$.

Figure 8 depicts an interaction plot illustrating the second order interaction between the VTMDS feed rate and the DTBPH feed rate (Figure 8). This is the only interaction affecting the grafting degree in this grafting reaction. The obvious effect of this synergism is that the positive effect of increasing VTMDS feed rate on the grafting degree is further enhanced by using higher feed rates of peroxide initiator, suggesting that overall a higher number of radicals is generated, initiating the grafting reaction.

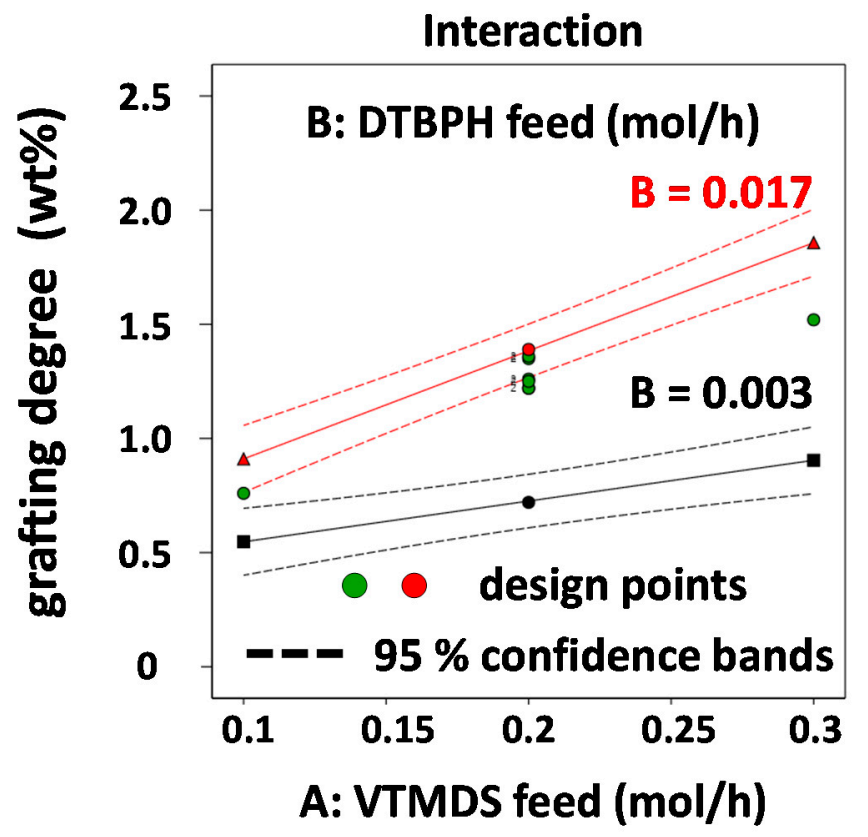

Figure 8. Interaction plot for the two-factor interactions between VTMDS and DTBPH feed rates $(\mathrm{AB})$ on the grafting degree response.

The effects of the two most important process factors on the grafting degree are visualized in Figure 9 as 3D response surface and contour line plots. Figure $9 a, b$ shows the effects of VTMDS and DTBPH feed rates at the highest value used for the temperature increase, whereas Figure $9 c, d$ shows these effects at the lowest value for the temperature increase. 

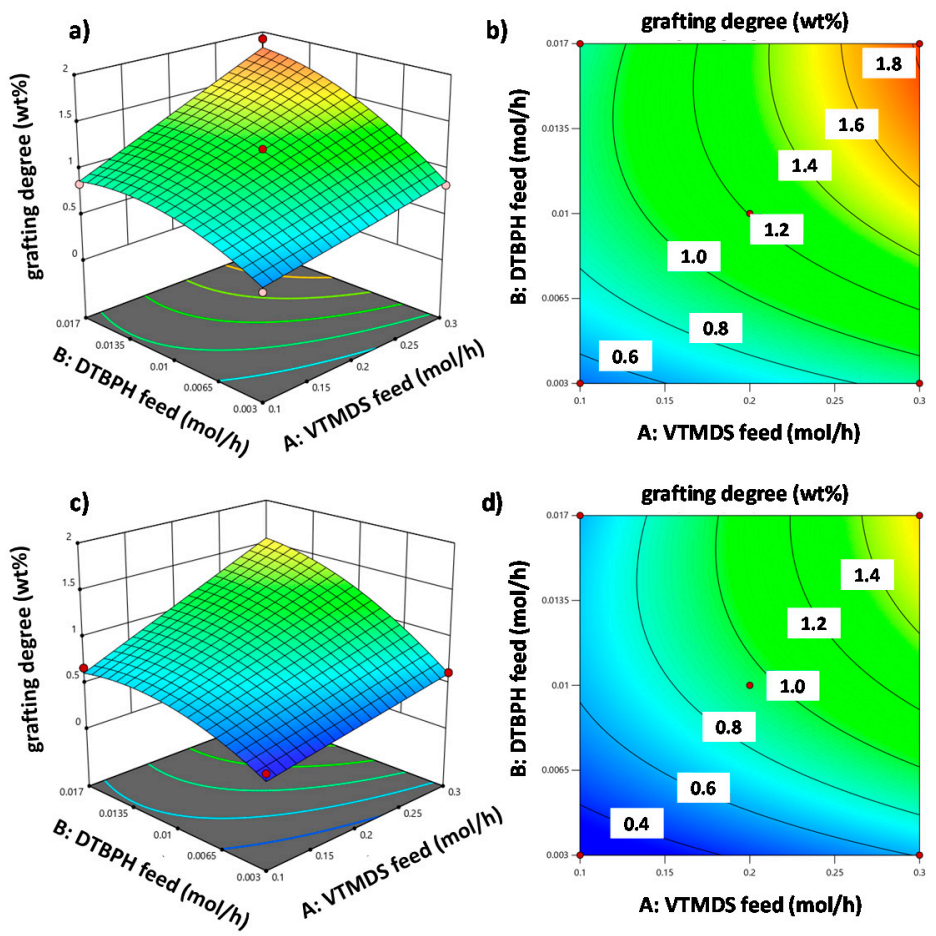

Figure 9. Grafting degree as a function of the VTMDS and DTBPH feed rates for two scenarios: (1) $3 \mathrm{D}$ response surface plot (a) and corresponding contour line plot (b) at the high level for the factor "temperature increase", and (2) 3D response surface plot (c) and corresponding contour line plot (d) at the low level for the factor "temperature increase".

The effects of process factor variations (i.e., the coefficients in the factor effects equation in terms of coded values) on grafting degree are in good agreement with the factor effects obtained in earlier studies of similar systems, in which the grafting reactions of vinyltrimethoxysilane (VTMS) onto ethylene-propylene (EPM) [2] and ethylene-octene copolymer (EOC) [4] via reactive extrusion were investigated using response surface methodology. The same overall trends were found in all three systems. All three reactive extrusion processes are governed by non-linear factor effects and the same types of second-order interaction effects. For instance, the linear components of the temperature effect on the degree of grafting were in a comparable order of magnitude in all systems: EPM-g-VTMS: 0.10 [2]; EOC-g-VTMS: 0.10 [4]; EPM-g-VTMDS: 0.13 (this work), although in [4] the temperature was varied within a slightly narrower range from $100{ }^{\circ} \mathrm{C}-220^{\circ} \mathrm{C}$ instead of $80^{\circ} \mathrm{C}$ to $220^{\circ} \mathrm{C}$. Although most effects were similar, some notable differences should be pointed out. While the linear factor effect of variations in the silane monomer feed rate on the grafting degree in the EPM-g-VTMDS system studied in the present work (0.33) is practically the same as that for the EPM-g-VTMS system (0.35), [2], it is only about $25 \%$ of the factor effect found for the EOC-g-VTMS system in Ulitzsch et al. [4] (1.17). Obviously, in the ethylene-octene copolymer (EOC) $\mathrm{H}$ is abstracted more readily and this seems to have a positive effect on the obtainable grafting degrees. The linear effect term for the peroxide feed rate, as another interesting difference, was of comparable magnitude in the EPM-g-VTMS (0.60) [2] and EOC-g-VTMS (0.66) [4] systems but is almost twice as large as the effect found for the EPM-g-VTMDS system (0.33) in the present study. This difference can be attributed to the nature of the grafting monomer VTMDS. Unlike VTMDS, VTMS carries three methoxy groups that exhibit a positive electron-inducing effect. This makes the double bond of VTMS more reactive. These differences illustrate the importance of considering the nature of the polymer backbone (type of polyolefin) and the nature of the grafting monomer (silane coupling reagent) when designing the grafting process. In all 
three systems, the interaction between the grafting monomer and peroxide initiator feed rates $(\mathrm{AB})$ was highly significant $[2,4]$.

\subsection{Effect of Process Variables on Grafting Efficiency}

To predict grafting efficiency, response surface analysis yielded a model containing seven relevant factor effect terms. Again, only terms with a $p$-value less than 0.05 were included. The ANOVA is presented in Table 5. With coefficients of determination $R^{2}=0.9772$, $R^{2}$ adjusted $=0.9638$ and $R^{2}$ predicted $=0.9206$, the model displayed good experimental fit, was not overfitted and yielded robust predictions.

Table 5. ANOVA for response surface analysis of grafting efficiency.

\begin{tabular}{cccccc}
\hline Source & $\begin{array}{c}\text { Degree of } \\
\text { Freedom }(\mathbf{d f})\end{array}$ & $\begin{array}{c}\text { Sum of } \\
\text { Squares }\end{array}$ & $\begin{array}{c}\text { Mean } \\
\text { Square }\end{array}$ & F-Value & $p$-Value \\
\hline Model & 5275.04 & 7 & 753.58 & 73.34 & $<0.0001$ \\
A-VTMDS feed & 2108.59 & 1 & 2108.59 & 205.22 & $<0.0001$ \\
B-DTBPH feed & 2259.91 & 1 & 2259.91 & 219.94 & $<0.0001$ \\
C-temperature increase & 358.92 & 1 & 358.92 & 34.93 & $<0.0001$ \\
AB & 72.24 & 1 & 72.24 & 7.03 & 0.0211 \\
A $^{2}$ & 177.2 & 1 & 177.2 & 17.25 & 0.0013 \\
B $^{2}$ & 163.59 & 1 & 163.59 & 15.92 & 0.0018 \\
C $^{2}$ & 132.17 & 1 & 132.17 & 12.86 & 0.0037 \\
Residual & 123.3 & 12 & 10.28 & & \\
Lack of Fit & 90.43 & 7 & 12.92 & 1.97 & 0.2372 \\
Pure Error & 32.87 & 5 & 6.57 & & \\
Cor Total & 5398.34 & 19 & & & \\
\hline
\end{tabular}

Grafting efficiency depends non-linearly on VTMS and DTBTH feed rates. These two factors are also the most important effects that mainly determine the system's behavior. They are both in the same order of magnitude. Increasing the VTMDS feed rate has a negative effect on grafting efficiency, whereas grafting efficiency is improved when the DTBPH feed rate is increased. Again, VTMDS and DTBPH feed rates are involved in a second-order interaction. Grafting efficiency also depends non-linearly on the temperature increase, although its overall effect is slightly smaller than the effects of the feed rates. The relative magnitudes of the significant effects are summarized in the factor effects equation in terms of coded factors: grafting efficiency VTMDS $(\%)=51.14-14.52 \times \mathrm{A}+15.03 \times$ $\mathrm{B}+5.99 \times \mathrm{C}-3.01 \times \mathrm{AB}+8.03 \times \mathrm{A}^{2}-7.71 \times \mathrm{B}^{2}-6.93 \times \mathrm{C}^{2}$.

The molar ratio between silane grafting agent and peroxide initiator had no effect on the grafting efficiency. Specific values for the grafting efficiency can be calculated from the factor effects equation in terms of actual values: grafting efficiency VTMDS (\%) = $+53.56777-423.37234 \times \mathrm{A}+6154.19481 \times \mathrm{B}+0.992823 \times \mathrm{C}-4292.85714 \times \mathrm{AB}+802.72727$ $\times \mathrm{A}^{2}-157403 \times \mathrm{B}^{2}-0.017332 \times \mathrm{C}^{2}$.

The interaction between VTMDS and DTBPH feed rates is visualized in the interaction plot presented in Figure 10.

The effects of the process factors on grafting efficiency are illustrated in Figure 11. The non-linear effects of all three factors and the second-order interaction effect cause the response surface to have the form of a twisted saddle, which is shown in the 3D response surface plot in Figure 11a. The contour line plot shown in Figure 11b enables quantitative conclusions to be drawn by projecting the response surface in two dimensions. In Figure 11, a scenario is depicted in which the level of the factor "temperature increase" is set to an intermediate level (the center point settings). 


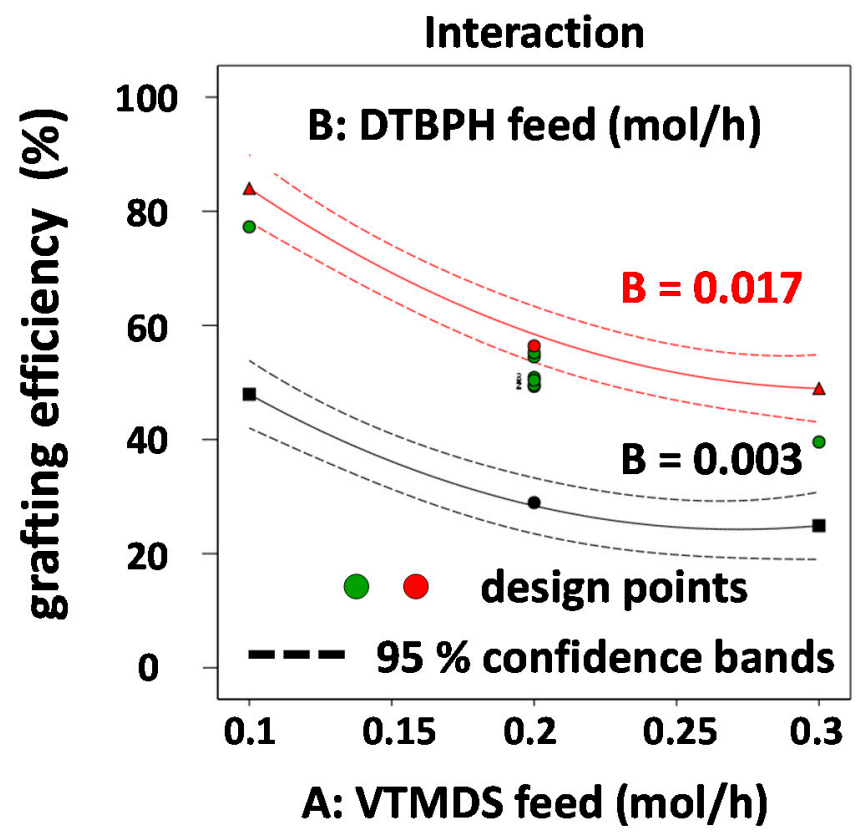

Figure 10. Interaction plot for the 2 FIAs of VTMDS and DTBPH feed rates $(A B)$ on the grafting efficiency response.
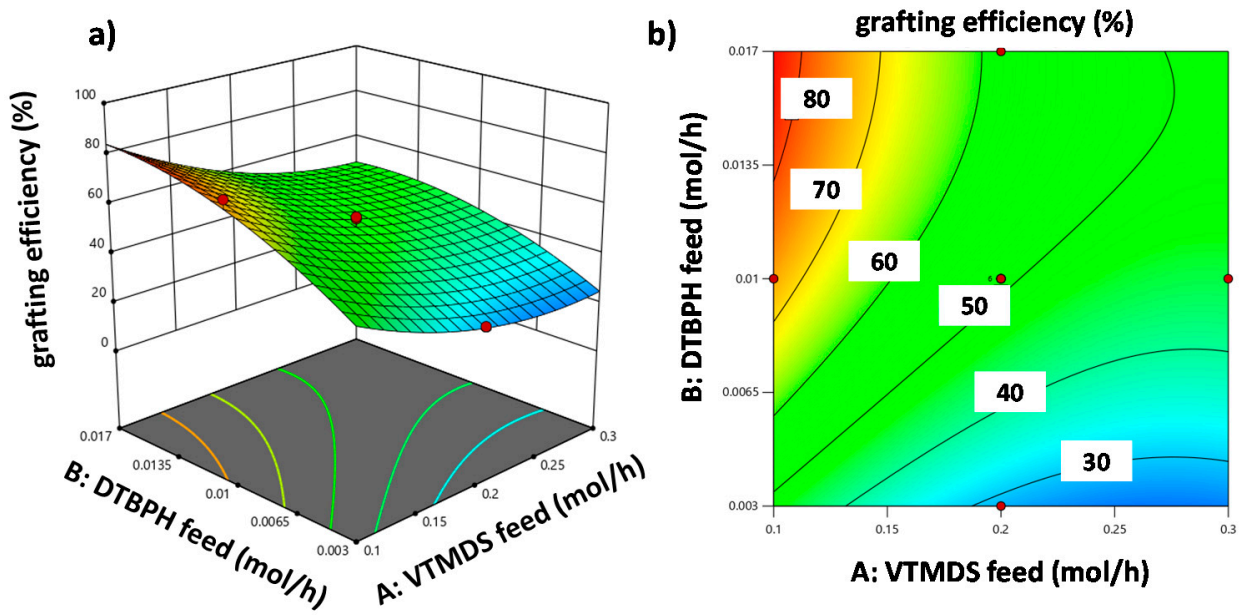

A: VTMDS feed $(\mathrm{mol} / \mathrm{h})$

Figure 11. (a) 3D response surface plot and (b) contour plot for the response grafting efficiency showing the dependence on VTMDS and DTBPH feed rates at intermediate factor level setting for the temperature increase.

As with the grafting degree, the factor effects on grafting efficiency (i.e., the coefficients of the factor effects equation in terms of coded factors) are also in good agreement with effects found earlier with the EPM-g-VTMS [2] and EOC-g-VTMS [4] systems. Again, the linear factor effect of peroxide feed rate is comparable in all three systems, with EPM-gVTMS: 17.8 [2], EOC-g-VTMS: 14.4 [4] and EPM-g-VTMDS: 15.0 (this work). The effect of silane monomer feed rate, however, although in the same order of magnitude with the VTMS systems (-10.0 [2] and -9.6) [4], was about 1.5 times larger in the EPM-g-VTMDS system (this work). Since in [2] and [4] VTMS was used as the grafting reagent, this difference is attributed to the chemical nature of VTMDS. 
The effect of temperature increases noticeably in the series EOC-g-VTMS [4] < EPM-gVTMS, [2] < EPM-g-VTMDS. In [2], liquid EPM was used, whereas in [4], EOC was applied as a solid granulate. Since in the present study and [2] the backbone polymer was the same, the additional positive effect on grafting efficiency observed is due to the different grafting monomer. Thus, VTMDS is more favorable for obtaining higher grafting efficiency than VTMS $[2,4]$.

\subsection{Process Window for the Grafting Reaction at Reactive Extrusion}

Both models, the one for the grafting degree and the one for the grafting efficiency are sufficiently good and can be used to define a process window which accounts for a good compromise between grafting degree and grafting efficiency. The hydride content of silicones is often given in terms of molality $(\mathrm{mmol} / \mathrm{g})$ in order to facilitate the dosage of appropriate molar ratios of the vinyl and hydride components for the hydrosilylation reaction. To obtain the hydride content in $\mathrm{wt}_{\mathrm{t}} \%$ the grafting degree is divided by $160(\mathrm{M}(\mathrm{H})=1 \mathrm{~g} / \mathrm{mol}$; $\mathrm{M}(\mathrm{VTMDS})=160 \mathrm{~g} / \mathrm{mol})$. hydride content $(\mathrm{wt} \%)=\frac{\mathrm{M}(\mathrm{H})}{\mathrm{M}(\mathrm{VTMDS})} \cdot$ grafting degree $(\mathrm{w} t \%)$. The molality is calculated by molality $(\mathrm{mmol} / \mathrm{g})=\frac{\text { hydride content }(\mathrm{wt} \%)}{\mathrm{M}(\mathrm{H})} \times \frac{1}{100 \%} \times \frac{1000 \mathrm{mmol}}{1 \mathrm{~mol}}$. Optimization of the reactive extrusion process is targeted at $0.1 \mathrm{mmol}$ hydride/g. This amount is favorable for subsequent crosslinking of the hydrosilylated polyolefin. This molality of $0.1 \mathrm{mmol}$ hydride/g corresponds to a grafting degree of $1.6 \%$.

Figure 12 shows the overlay plot defining the process window to obtain a grafting degree $1.55 \mathrm{wt} \%-1.64 \mathrm{wt} \%$ at a grafting efficiency $>50 \%$. In this optimization scenario, reactive extrusion is run at the intermediate setting for the temperature increase (i.e., the $\mathrm{CP}$ setting). This corresponds to a temperature range from $100^{\circ} \mathrm{C}$ to $200^{\circ} \mathrm{C}$. The area colored in yellow highlights all possible combinations of VTMDS and DTBPH feed rates at this temperature increase that yield satisfactory grafting degrees and grafting efficiencies.

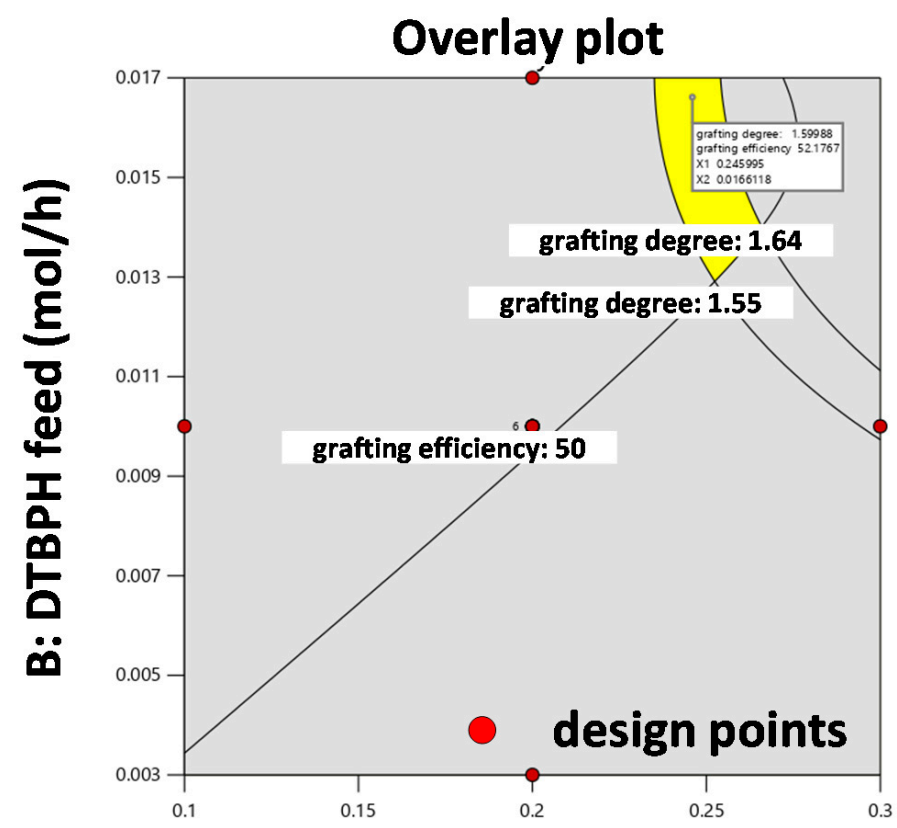

A: VTMDS feed $(\mathrm{mol} / \mathrm{h})$

Figure 12. Overlay plot for the process window of $1.55 \mathrm{wt} \%-1.64 \mathrm{wt} \%$ grafting degree and grafting efficiency of $>50 \%$ with the target of $1.6 \mathrm{wt} \%$ grafting degree with the correlation of VTMDS feed and DTBPH feed and all other factors at intermediate factor-level settings. 
The process parameters calculated for the validation experiment are shown in Figure 13. The selected combination was calculated to achieve a molality of $0.1 \mathrm{mmol}$ hydride/g, which corresponds to a grafting efficiency of $1.6 \mathrm{wt} \%$ VTMDS. The grafting efficiency here was expected to be maximized and was predicted to be $52 \%$. The temperature increase covered a temperature range of $100{ }^{\circ} \mathrm{C}-200{ }^{\circ} \mathrm{C}$. The VTMDS feed was set to $0.2478 \mathrm{~mol} / \mathrm{h}$ and the DTBPH feed was set to $0.0162 \mathrm{~mol} / \mathrm{h}$.
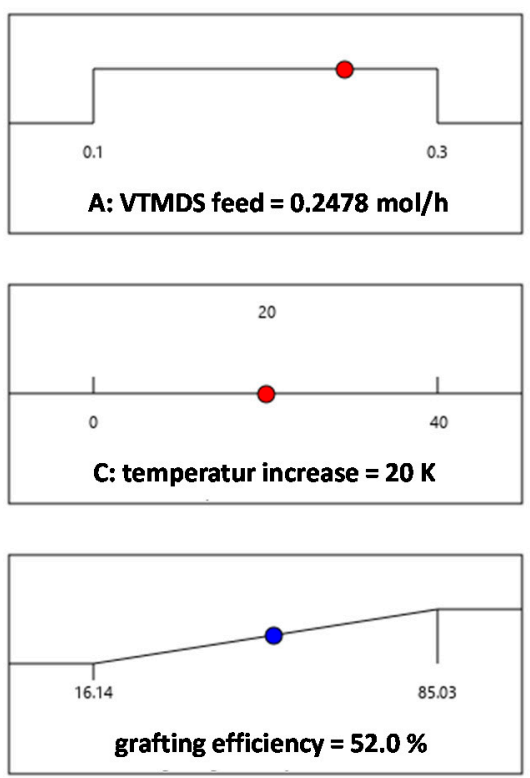

Figure 13. Process optimization for a grafting degree of $1.6 \mathrm{wt} \%$ and high grafting efficiency.

The validation experiment resulted in a grafting degree of $1.64 \mathrm{wt} \%$, corresponding to a molality of $0.10 \mathrm{mmol}$ hydride/g. The grafting efficiency was also within the target range, at $53.17 \%$, indicating that the models for both target responses are valid and lead to reliable predictions.

\subsection{Data Selection and Pre-Processing for Multivariate Analysis}

In this work, in-line Raman spectroscopy was combined with multivariate data analysis for the characterization of the process to determine the proportions of VTMDS and to predict the grafting degree of the final product. A total of 20 trials were run in a randomized trial sequence. During each experimental run, Raman spectra were continuously recorded in-line every $30 \mathrm{~s}$, to monitor the entire process. All spectra distorted by measuring artefacts, caused for instance by gas bubbles, were eliminated from the data set. The dataset contained only spectra obtained under stable process conditions after adjusting the pre-defined process factor-level settings.

Principal component analysis (PCA) with 188 spectra from all 19 experiments was used to quantify the VTMDS concentration. Spectra from 17 experiments were used for the calibration model for the PLS-R of the grafting degree. For a low and a high grafting degree, two randomly selected experiments were taken for external validation. The details of the respective experiments and models can be found in Table 6.

All Raman spectra were preprocessed using the Savitzky-Golay 1st derivative (smoothed, symmetric 21 points, 2nd polynomial order). They are shown in Figure 14.

To interpret the in-line Raman spectra, which contained superimposed information of the entire process, they were compared with off-line Raman spectra obtained from the pure substances of the reactants (EPM and VTMDS) and the product EPM-g-VTMDS (Figure 15). The in-line process spectra contain information not only on the mixture of the three pure substances, but also on the initiator present in traces and other potential by-products. They also reflect the effects of all variations in process parameter settings introduced during 
the factorial experiment. Shifts in the bands are possible while comparing the in-line and off-line spectra since the surrounding matrix has an influence on the polarizability of the electron shell of the molecule and thus on the position of the Raman bands. In addition, different Raman instruments were used for recording the in-line and the off-line spectra. Therefore, spectral ranges of Raman oscillations instead of specific single values for the Raman vibration bands are given for the relevant signals in the in-line spectra.

Table 6. Calibration set for determination of VTMDS and grafting degree via in-line Raman spectroscopy.

\begin{tabular}{ccc}
\hline Set No. & $\begin{array}{c}\text { PCA VTMDS } \\
\text { mol/h }\end{array}$ & $\begin{array}{c}\text { Partial Least Squares Regression (PLS-R) } \\
\text { Grafting Degree wt } \%\end{array}$ \\
\hline 1 & 0.1 & 0.67 \\
2 & 0.5 & 1.43 \\
3 & 0.3 & 1.35 \\
4 & 0.1 & 0.76 \\
5 & 0.1 & 0.46 \\
6 & 0.1 & 0.84 \\
7 & 0.3 & 1.36 \\
8 & 0.3 & 1.22 \\
9 & 0.3 & $1.39 *$ \\
10 & 0.5 & 1.52 \\
11 & 0.3 & $0.72 *$ \\
12 & 0.3 & 1.22 \\
13 & 0.3 & 1.26 \\
14 & 0.3 & 0.93 \\
15 & 0.1 & 0.33 \\
16 & 0.3 & 1.25 \\
17 & 0.3 & 1.26 \\
18 & 0.5 & 0.83 \\
19 & 0.5 & 1.92 \\
\hline
\end{tabular}

* not used for PLS-R calibration model, only for PLS-R validation.
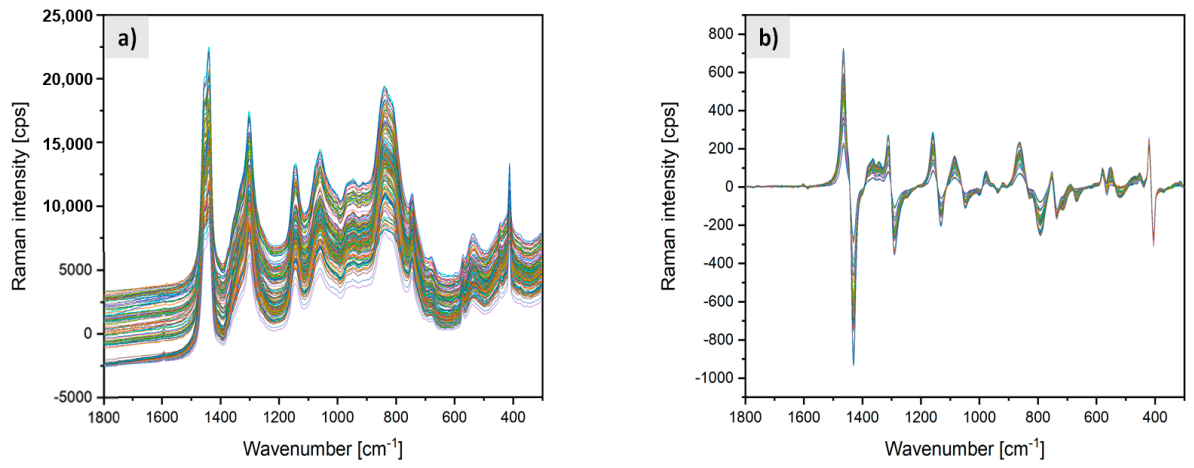

Figure 14. (a) Time series of in-line Raman spectra taken during the reactive extrusion process, (b) spectra after pre-processing with spectral pre-processing by the Savitzky-Golay 1st (smoothed) derivative (symmetric 21 points, 2nd polynomial order). 


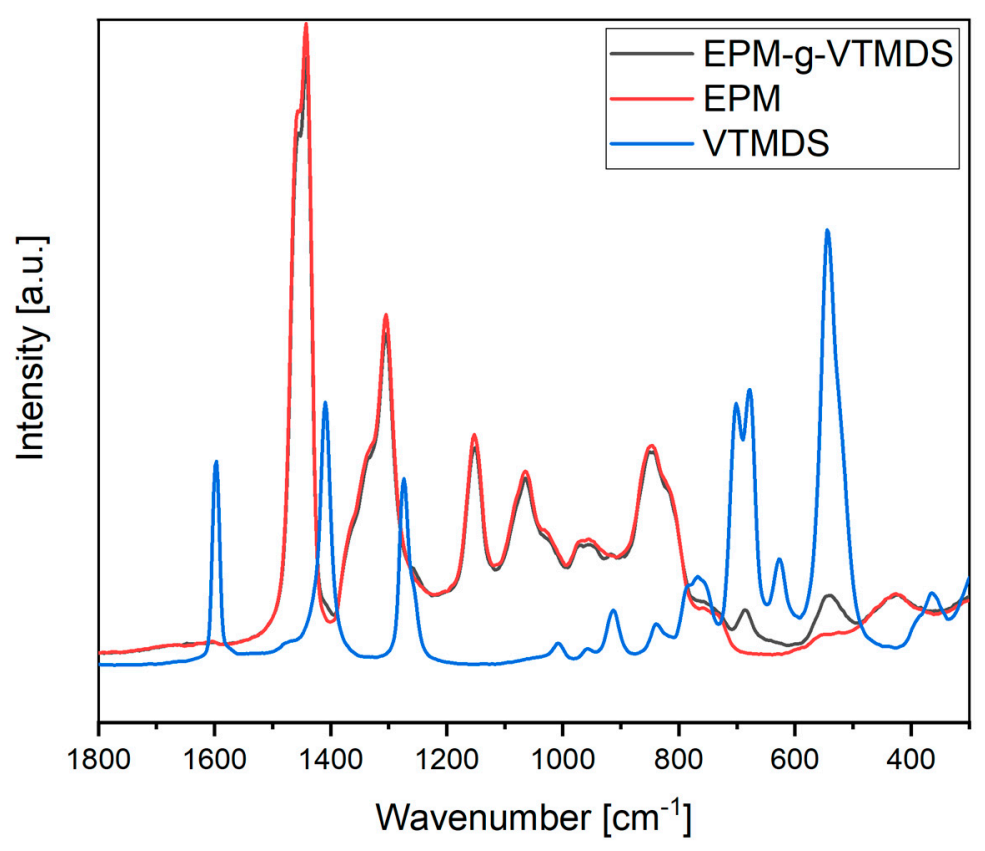

Figure 15. Off-line Raman spectra of VTMDS, EPM and EPM-g-VTMDS.

The predominant information visible in the in-line Raman data is very similar to that of pure EPM. Since EPM forms the backbone for the grafted polymer and thus constitutes the bulk of the reactant, this is reflected by the spectral signature of the process. Raman active bands in EPM are mainly $\mathrm{C}-\mathrm{C}-\mathrm{C},-\mathrm{CH}_{2}-$ or $-\mathrm{CH}_{3}-$ vibrations. For example, the C $-\mathrm{C}-\mathrm{C}$ vibrations for aliphatic and branched polymers occur from $1100-1040 \mathrm{~cm}^{-1}$, at $970 \mathrm{~cm}^{-1}$, from $900-800 \mathrm{~cm}^{-1}$, from $540-485 \mathrm{~cm}^{-1}$ and at $300 \mathrm{~cm}^{-1}$. Between $1305 \mathrm{~cm}^{-1}$ and $1295 \mathrm{~cm}^{-1}$ is the medium-strength $-\left(\mathrm{CH}_{2}\right)_{\mathrm{n}}-$ deformation vibration, and at $735 \mathrm{~cm}^{-1}$ the $-\left(\mathrm{CH}_{2}\right)_{3}-$ rocking vibration. In the spectral range between $560 \mathrm{~cm}^{-1}$ and $420 \mathrm{~cm}^{-1}$ the $\mathrm{CH}_{2}$ wagging, $\mathrm{C}-\mathrm{CH}_{3}$ stretching and $\mathrm{CH}_{2}$ rocking vibrations are found with different intensities. For the monomer VTMDS, the $\mathrm{Si}-\mathrm{CH}=\mathrm{CH}_{2}$ vibrations from $1615-1590 \mathrm{~cm}^{-1}$ (C=C stretching), from $1410-1390 \mathrm{~cm}^{-1}\left(\mathrm{CH}_{2}\right.$ in plan deformation), $1020-1000 \mathrm{~cm}^{-1}$ (trans $\mathrm{CH}$ wagging) and from $980-940 \mathrm{~cm}^{-1}\left(\mathrm{CH}_{2}\right.$ wagging) are Raman-active. Moreover, between $985-800 \mathrm{~cm}^{-1}$ lies the $\mathrm{Si}-\mathrm{H}$ wagging deformation. Furthermore, between $770 \mathrm{~cm}^{-1}$ and $675 \mathrm{~cm}^{-1}$ are different $\mathrm{Si}-\mathrm{C}$ vibrations. The symmetric $\mathrm{Si}-\mathrm{O}-\mathrm{Si}$ vibration is most pronounced between $625-480 \mathrm{~cm}^{-1}$ in the off-line spectra. However, since the monomer is a much smaller molecule relative to EPM, these vibrations are strongly superimposed by other signals in the in-line process spectra and are not clearly discernible. The same applies to the subtle differences between EPM and the EPM-g-VTMDS product. The spectral differences are only weakly pronounced even in the off-line spectra of the pure substances. At $763 \mathrm{~cm}^{-1}$, an additional shoulder can be seen in the grafted product that is not present in the EPM starting material. The strongly Raman-active $\mathrm{Si}-\mathrm{C}$ stretching band is located in this region. Additional signals can also be seen at $687 \mathrm{~cm}^{-1}$ and at $540 \mathrm{~cm}^{-1}$. The signal at $687 \mathrm{~cm}^{-1}$ is assigned to the $\mathrm{Si}-\mathrm{C}$ stretching vibration. Between $625 \mathrm{~cm}^{-1}$ and $480 \mathrm{~cm}^{-1}$ the very strong symmetric $\mathrm{Si}-\mathrm{O}-\mathrm{Si}$ stretching vibration occurs. Minimal decreases in the signal intensities are also seen in EPM-g-VTMDS. These are observed at $1454 \mathrm{~cm}^{-1}, 1442 \mathrm{~cm}^{-1}, 846 \mathrm{~cm}^{-1}$ and $820 \mathrm{~cm}^{-1}$. The signals between $1456-1440 \mathrm{~cm}^{-1}$ can be assigned to asymmetric $-\mathrm{CH}_{3}$ vibrations of aliphatic polymers. The changes at $846 \mathrm{~cm}^{-1}$ and $820 \mathrm{~cm}^{-1}$ are caused by changes in the polarizability of the electron shell of the $\mathrm{C}-\mathrm{C}-\mathrm{C}$ backbone. Further details regarding band assignment and the location of the bands found in the off-line Raman spectra are given in Table 7. 
Table 7. Relevant Raman bands for VTMDS, EPM and EPM-g-VTMDS.

\begin{tabular}{|c|c|c|c|}
\hline $\begin{array}{l}\text { Position Raman Band } \\
\text { Off-Line }\left(\mathrm{cm}^{-1}\right)\end{array}$ & $\begin{array}{l}\text { Literature Range } \\
\qquad\left(\mathrm{cm}^{-1)}\right.\end{array}$ & Molecule Group & Vibration \\
\hline 1597 & $1615-1590$ & $\mathrm{Si}-\mathrm{CH}=\mathrm{CH}_{2}$ & $\mathrm{C}=\mathrm{C}$ stretching \\
\hline 1442 & $1456-1440$ & $-\mathrm{CH}_{3}$ aliphatic & asymmetric \\
\hline 1409 & $1410-1390$ & $\mathrm{Si}-\mathrm{CH}=\mathrm{CH}_{2}$ & $\mathrm{CH}_{2}$ in plane deformation vibration \\
\hline 1305 & $1305-1295$ & $-\left(\mathrm{CH}_{2}\right)_{\mathrm{n}}-$ & $\mathrm{CH}_{2}$ deformation vibration \\
\hline 1274 & $1290-1240$ & $\mathrm{Si}-\left(\mathrm{CH}_{3}\right)$ & Sharp symmetric $\mathrm{CH}_{3}$ deformation vibration \\
\hline 1153 & $1175-1120$ & $\mathrm{C}-\mathrm{C}-\mathrm{C}$ & $\mathrm{C}-\mathrm{C}-\mathrm{C}$ vibration \\
\hline 1065 & $1100-1040$ & $\mathrm{C}-\mathrm{C}-\mathrm{C}$ aliphatic & $\mathrm{C}-\mathrm{C}-\mathrm{C}$ vibration \\
\hline 1039 & $1100-1040$ & $\mathrm{C}-\mathrm{C}-\mathrm{C}$ branched & $\mathrm{C}-\mathrm{C}-\mathrm{C}$ vibration \\
\hline 1008 & $1020-1000$ & $\mathrm{Si}-\mathrm{CH}=\mathrm{CH}_{2}$ & Trans $\mathrm{CH}$ wagging vibration \\
\hline 970 & 973 & $\mathrm{C}-\mathrm{C}-\mathrm{C}$ branched & $\mathrm{C}-\mathrm{C}-\mathrm{C}$ stretching \\
\hline 958 & $980-940$ & $\mathrm{Si}-\mathrm{CH}=\mathrm{CH}_{2}$ & $\mathrm{CH}_{2}$ wagging vibration \\
\hline 913 & $985-800$ & $\mathrm{Si}-\mathrm{H}$ & $\mathrm{Si}-\mathrm{H}$ deformation vibration \\
\hline 846 & $900-800$ & $\mathrm{C}-\mathrm{C}-\mathrm{C}$ & $\mathrm{C}-\mathrm{C}-\mathrm{C}$ vibration \\
\hline 839 & $870-760$ & $\mathrm{Si}-\mathrm{CH}_{3}$ & $\mathrm{Si}-\mathrm{CH}_{3}$ rocking vibration \\
\hline 768 & 765 & $\mathrm{Si}-\mathrm{C}$ & $\mathrm{Si}-\mathrm{C}$ stretching \\
\hline 737 & $735-725$ & $-\left(\mathrm{CH}_{2}\right)_{3}-$ & $-\left(\mathrm{CH}_{2}\right)_{3}-$ rocking vibration \\
\hline 701 & $705-670$ & $\mathrm{Si}-\mathrm{C}$ & $\mathrm{Si}-\mathrm{C}$ stretching \\
\hline 678 & $705-670$ & $\mathrm{Si}-\mathrm{C}$ & $\mathrm{Si}-\mathrm{C}$ stretching \\
\hline 628 & $624-580$ & $\mathrm{Si}-\mathrm{O}-\mathrm{Si}$ & $\mathrm{Si}-\mathrm{O}-\mathrm{Si}$ broad symmetric stretching \\
\hline 554 & $555-530$ & $\mathrm{C}-\mathrm{CH}_{3} /-\mathrm{CH}_{2}$ & $\mathrm{CH}_{2}$ wagging, $\mathrm{C}-\mathrm{CH}_{3}$ stretching, $\mathrm{CH}_{2}$ rocking \\
\hline 545 & $625-480$ & $\mathrm{Si}-\mathrm{O}-\mathrm{Si}$ & $\mathrm{Si}-\mathrm{O}-\mathrm{Si}$ broad symmetric stretching \\
\hline 526 & $540-485$ & $\mathrm{C}-\mathrm{C}-\mathrm{C}$ & $\mathrm{C}-\mathrm{C}-\mathrm{C}$ vibration \\
\hline 426 & $460-420$ & $\mathrm{CH}_{2}$ & Wagging $\mathrm{CH}_{2}$ \\
\hline 303 & 300 & $\mathrm{C}-\mathrm{C}-\mathrm{C}$ & broad $\mathrm{C}-\mathrm{C}-\mathrm{C}$ vibration \\
\hline
\end{tabular}

The use of an in situ real-time process analyzer for monitoring the grafting degree was investigated. In order to extract and interpret the superimposed and relevant information, multivariate methods PCA and PLS-R were applied.

\subsection{Determination of VTMDS Content Using PCA}

PCA was used to restructure the preprocessed spectroscopic data of all 19 sample sets along the maximum variance. The range from $1800 \mathrm{~cm}^{-1}$ to $300 \mathrm{~cm}^{-1}$ was investigated. The model based on two principal components explained the data variance sufficiently well (at $97 \%$ ) and was used for modeling the VTMDS feed. The model was verified by random cross validation with 20 segments. Each dot shown in the graph in Figure 16a represents a Raman spectrum. The closer the dots are in the scores plot (Figure 16a), the more similar they are with respect to the PCs concerned. Conversely, samples that are more distant from each other are spectroscopically more different. The plot can be used to interpret differences and similarities among spectra. Together with the corresponding loadings plots (Figure 16b-c) for the same two components it is possible to determine which variables in the data set structured by the DoE plan are responsible for differences between sample sets.

In PC1, no clear sample grouping was evident. Possibly, the maximum variance in the data indicated the differences in the process settings and thus in the individual experiments as a whole. Temperature, the amount of initiator used (peroxide content) and the monomer feed of VTMDS were varied. Thus, the polymer was grafted to varying grafting degrees. This sum of differences in the sample sets was expressed by PC1. Furthermore, in the corresponding loadings for PC1 (Figure 16b), for example, the bands in the range $1460-1440 \mathrm{~cm}^{-1}\left(-\mathrm{CH}_{3}\right), 1310-1290 \mathrm{~cm}^{-1}\left(-\left(\mathrm{CH}_{2}\right)_{\mathrm{n}}-\right)$ and $1160-1130 \mathrm{~cm}^{-1}(\mathrm{C}-\mathrm{C}-\mathrm{C})$, indicate changes in the polarizability of the electron shell of the molecule and its surrounding matrix. 

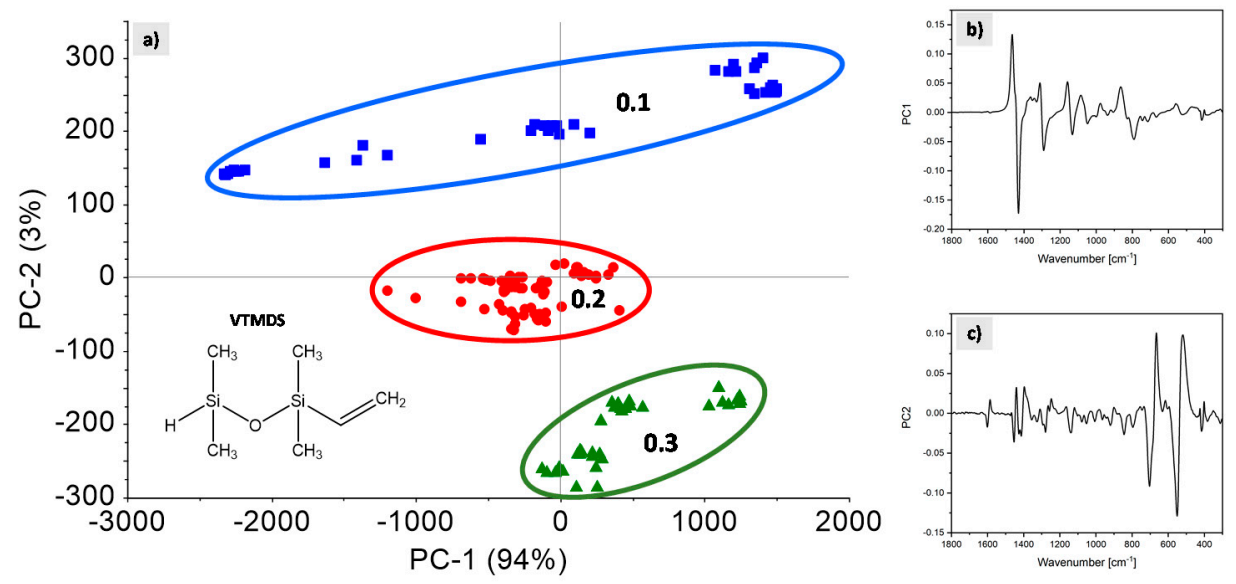

Figure 16. (a) Scatter plot for PC1 and PC2. Loadings for (b) PC1 and (c) PC2.

In contrast, distinct sample groupings were identified in PC2. Along the PC2 axis, clustering of the Raman spectra with respect to the applied variations in VTMDS feed rate is visible. The different experimental settings are highlighted in Figure 16a with different colors: $0.1 \mathrm{~mol} / \mathrm{h}$ (blue), $0.2 \mathrm{~mol} / \mathrm{h}$ (red) and $0.3 \mathrm{~mol} / \mathrm{h}$ (green). This suggests that changes visible in PC2 can be attributed to variations in VTMDS feed rates. In the loadings plot for PC2 (Figure 16c) those bands where the largest changes upon variations in VTMDS feed rate occur can be identified and interpreted. The loadings at around $1410 \mathrm{~cm}^{-1}$ are assigned to the $\mathrm{CH}_{2}$ in plane deformation vibrations of the $\mathrm{Si}-\mathrm{CH}=\mathrm{CH}_{2}$ group. The loadings at around $800 \mathrm{~cm}^{-1}$ are characteristic for the $\mathrm{Si}-\mathrm{H}$ deformation vibration. The bands between $625 \mathrm{~cm}^{-1}$ and $580 \mathrm{~cm}^{-1}$ are assigned to the $\mathrm{Si}-\mathrm{O}-\mathrm{Si}$ stretching vibrations. The characteristic bands with high loadings reflect variations in the concentration of the silane monomer feed.

This allows the monitoring of the VTMDS feed concentration in-line during the process and, in turn, allows real-time quality control of the extrusion process, helping to make the process faster, more efficient and more cost-effective. It provides a knowledge basis for quantifying the grafting monomer in-line using PLS-R and thus also to quantify the grafting degree.

\subsection{Determination of Grafting Degree via PLS-R}

The in-line Raman data set preprocessed (smoothed, symmetric 21 points, 2nd polynomial order) after the 1st Savitzky-Golay derivation was analyzed using PLS-R. In this analysis, spectral features were extracted from the dataset via PLS-R according to the degree of grafting, given in $w t \%$, from the complex and superimposed information. To this end, the in-line Raman spectra were correlated with the values for the grafting degree as determined by NMR analysis. It was verified that in-line Raman spectroscopy provided an alternative to the costly and time-consuming NMR off-line analysis, thus avoiding the time lag between the process and subsequent analysis of the reaction product. PLS-R effectively reduces the spectral data matrix to a set of orthogonal factors that are predictive of the chemical composition and describes as much as possible of the observed variance in the spectra [17].

As revealed by comparing the in-line and off-line Raman spectra of the pure substances, the main spectral differences between EPM and EPM-g-VTMDS are found in the wavenumber range between $900 \mathrm{~cm}^{-1}$ and $300 \mathrm{~cm}^{-1}$. Focusing on these differences, the grafting degree becomes observable in the spectra and consequently this spectral range was used for the PLS-R analysis. The model, calculated with four factors, explained a total of $95 \%$ of the data variance. The coefficient of correlation $r$ between the predicted and the reference values in the plot (Figure 17a) is 0.975 and the corresponding Pearson coefficient of determination $R^{2}$ is 0.950 , illustrating that the calibration model for the grafting degree $\mathrm{wt} \%$ is sufficient. The good quality of the PLS-R model is also evident from the root mean 
square error of calibration (RMSEC), which describes the dispersion of the calibration samples about the regression line and is satisfactorily low (RMSEC $=0.093 \mathrm{wt} \%$ ). Similarly, the standard error of calibration (SEC), which is RMSEC corrected for bias (i.e., by the mean value over all data points that either lie systematically above or below the regression line), is also very small (SEC $=0.093 \mathrm{wt} \%$ ). With a difference between RMSEC and SEC of zero, bias is clearly not significant.
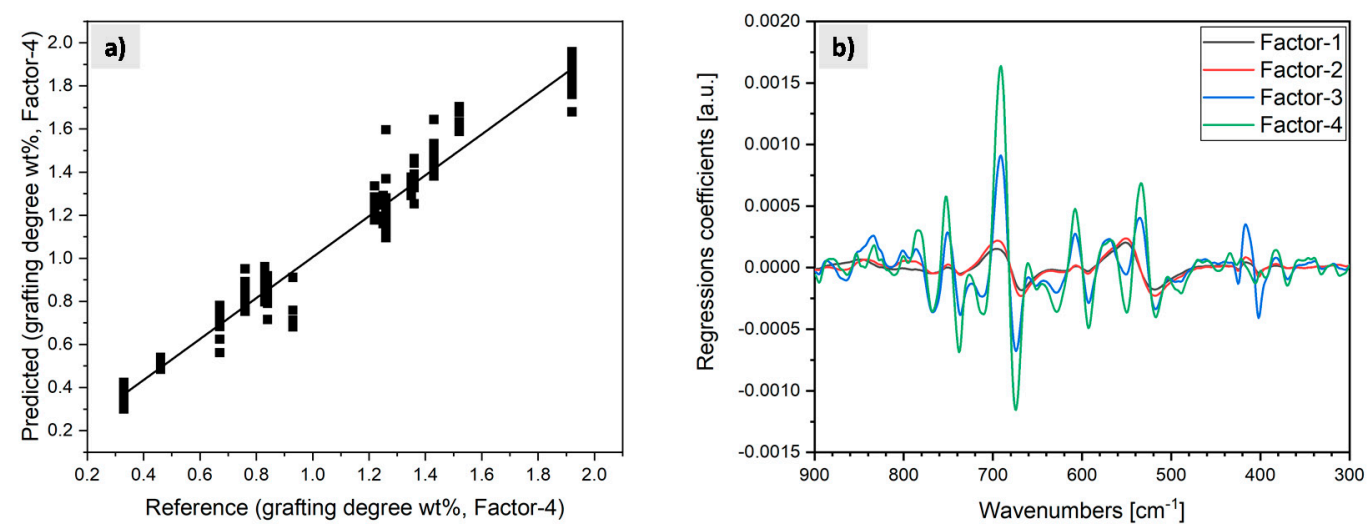

Figure 17. (a) Predicted vs. reference values of grafting degree for factor 4 and (b) regression coefficients for factors $1-4$.

The regression coefficients in Figure 17b summarize the relationship between all predictors, the spectral data and the "grafting degree" response in wt\%. A large regression coefficient has a large contribution to the modeled response value and hence the corresponding spectral range is important for predicting the grafting degree. In Figure $17 \mathrm{~b}$ the relative importance of various wavelength ranges to the four model factors can be discerned. It can be observed that all four factors are required to build the model.

The most important regression coefficients for predicting the grafting degree were between $760 \mathrm{~cm}^{-1}$ and $680 \mathrm{~cm}^{-1}$. In this spectral range, changes in $\mathrm{Si}-\mathrm{C}$ stretching vibrations are observed. This suggests a positive correlation of the Raman spectra with the grafting degree. A change in the $\mathrm{Si}-\mathrm{O}-\mathrm{Si}$ stretching vibrations is also observed between $610 \mathrm{~cm}^{-1}$ and $570 \mathrm{~cm}^{-1}$ and is described by the regression coefficients. The effect of variations in the process conditions on the $\mathrm{C}-\mathrm{C}-\mathrm{C}$ framework is evident from the bands around $540 \mathrm{~cm}^{-1}$. On this basis, a PLS-R model allowing the prediction of the grafting degree in $w \mathrm{t} \%$ during the reactive extrusion process was developed. The in-line Raman spectra were regressed versus the known grafting degree in $w t \%$, calculated from the off-line NMR data.

For external model validation, spectra from two material samples with different grafting degrees that were not included in the model building were used and processed with data pre-processing as before in the PLS-R model. The values predicted by the Ramanbased model for the grafting degree of these samples were, for the low grafting degree, $0.72 \mathrm{wt} \%$ on average, with a standard deviation of $\pm 0.07 \mathrm{wt} \%$. For the high grafting degree, the value was $1.42 \mathrm{wt} \% \pm 0.10 \mathrm{wt} \%$. During the in-line measurements, small variations in grafting degree were observed. For the subsequent off-line ${ }^{1} \mathrm{H}$ NMR analysis, these samples were already homogenized by diffusion in the melt. ${ }^{1} \mathrm{H}$ NMR spectroscopy yielded grafting degrees of $0.72 \mathrm{wt} \%$ for the low-grade grafting and $1.39 \mathrm{wt} \%$ for the higher-grade grafting. These values are in good agreement with the ones predicted by the PLS-R model based on the in-line Raman spectra and yield very accurate predictions. Since the off-line NMR data correlate very well with the in-line Raman spectra, it is concluded that the grafting process can be monitored in real-time based on in-line Raman spectroscopy. Thus, the complex and costly NMR spectroscopic off-line quality control with a large time-lag can be substituted by real-time in-line Raman measurements. 


\section{Conclusions}

We have presented the synthesis of a novel addition-crosslinkable synthetic rubber based on VTMDS-modified EPM with potential application as a high performance material in various areas. The reactive extrusion process was monitored in-line using a Raman spectroscopic in-situ probe embedded in the extrusion equipment in close proximity to the die tip. It was shown that both the consumption of silane grafting reagent and grafting degree in the EPM-g-VTMDS rubber can be well measured and controlled by process ana-lytical methods in real-time. Process windows for producing this new material with a high grafting efficiency were defined using response surface methodology. The effects and interaction effects of the most relevant process factors were identified and quantified by applying an orthogonal experimental design. It was found that the extrusion process depended in a non-linear and synergistic way on all studied process factors. The VTMDS and DTBPH feed rates were the most important process factors and were involved in synergistic interactions.

Author Contributions: Conceptualization, S.U., T.B., T.C., A.K. and G.L.; methodology, S.U. and A.K.; formal analysis, S.U.; investigation, S.U. and T.B.; resources, A.K., G.L. and T.C.; data curation, S.U.; writing—original draft preparation, S.U., M.S. and A.K.; writing—review and editing, A.K., G.L., T.C., T.B., S.U., M.S. and M.B.; visualization, S.U. and A.K.; supervision, A.K., G.L., M.B. and T.C.; project administration, T.B. and S.U.; funding acquisition, A.K., G.L. and T.C. All authors have read and agreed to the published version of the manuscript.

Funding: This research was funded by the Federal Ministry of Education and Research (BMBF), project number 03ET6082C. The article processing charge was funded by the Baden-Württemberg Ministry of Science, Research and Culture in the funding program Open Access Publishing.

Institutional Review Board Statement: Not applicable.

Informed Consent Statement: Not applicable.

Data Availability Statement: Data are available upon request from the authors.

Acknowledgments: The authors would like to express their thanks to Dominik Brzecki and Priska Kolb from the University of Tübingen for performing NMR measurements.

Conflicts of Interest: The authors declare no conflict of interest.

\section{References}

1. Patterson, R.; Kandelbauer, A.; Müller, U.; Lammer, H. Crosslinked Thermoplastics. In Handbook of Thermoset Plastics; Dodiuk, H., Ed.; Elsevier: Amsterdam, The Netherlands, 2021.

2. Bäuerle, T.; Ulitzsch, S.; Lorenz, A.; Rebner, K.; Chassé, T.; Kandelbauer, A.; Lorenz, G. Effects of process parameters on silane grafting of liquid ethylene-propylene copolymer by reactive extrusion as quantified by response surface methodology. Polymer 2020, 202, 122601. [CrossRef]

3. Lü, R. Die Entwicklung Vernetzbarer Polyolefinblends und Deren Verarbeitung zu Schmelzgesponnenen Elastomerfasern. 2003. Available online: https: / / elib.uni-stuttgart.de/handle/11682/1621 (accessed on 27 March 2021).

4. Ulitzsch, S.; Bäuerle, T.; Chassé, T.; Lorenz, G.; Kandelbauer, A. Optimizing the Process Efficiency of Reactive Extrusion in the Synthesis of Vinyltrimethoxysilane-Grafted Ethylene-Octene-Copolymer (EOC-g-VTMS) by Response Surface Methodology. Polymer (Basel) 2020, 12, 2798. [CrossRef] [PubMed]

5. Tan, J.; Chao, Y.J.; Wang, H.; Gong, J.; van Zee, J.W. Chemical and mechanical stability of EPDM in a PEM fuel cell environment. Polym. Degrad. Stab. 2009, 94, 2072-2078. [CrossRef]

6. Lin, C.-W.; Chien, C.-H.; Tan, J.; Chao, Y.J.; van Zee, J.W. Chemical degradation of five elastomeric seal materials in a simulated and an accelerated PEM fuel cell environment. J. Power Sources 2011, 196, 1955-1966. [CrossRef]

7. Cui, T.; Chao, Y.J.; Chen, X.M.; van Zee, J.W. Effect of water on life prediction of liquid silicone rubber seals in polymer electrolyte membrane fuel cell. J. Power Sources 2011, 196, 9536-9543. [CrossRef]

8. Tan, J.; Chao, Y.J.; Yang, M.; Lee, W.-K.; van Zee, J.W. Chemical and mechanical stability of a Silicone gasket material exposed to PEM fuel cell environment. Int. J. Hydrogen Energy 2011, 36, 1846-1852. [CrossRef]

9. Lin, C.-W.; Chien, C.-H.; Tan, J.; Chao, Y.-J.; van Zee, J.W. Dynamic mechanical characteristics of five elastomeric gasket materials aged in a simulated and an accelerated PEM fuel cell environment. Int. J. Hydrogen Energy 2011, 36, 6756-6767. [CrossRef] 
10. Nah, C.; Kim, S.G.; Shibulal, G.S.; Yoo, Y.H.; Mensah, B.; Jeong, B.-H.; Hong, B.K.; Ahn, J.-H. Effects of curing systems on the mechanical and chemical ageing resistance properties of gasket compounds based on ethylene-propylene-diene-termonomer rubber in a simulated fuel cell environment. Int. J. Hydrogen Energy 2015, 40, 10627-10635. [CrossRef]

11. Dietrich, A.; Mejía, E. Investigations on the hydrosilylation of allyl cyanide: Synthesis and characterization of cyanopropylfunctionalized silicones. Eur. Polym. J. 2020, 122, 109377. [CrossRef]

12. Guo, D.-J.; Han, H.-M.; Xiao, S.-J.; Dai, Z.-D. Surface-hydrophilic and protein-resistant silicone elastomers prepared by hydrosilylation of vinyl poly(ethylene glycol) on hydrosilanes-poly(dimethylsiloxane) surfaces. Colloids Surf. A Physicochem. Eng. Asp. 2007, 308, 129-135. [CrossRef]

13. Putzien, S.; Nuyken, O.; Kühn, F.E. Functionalized polysilalkylene siloxanes (polycarbosiloxanes) by hydrosilylation-Catalysis and synthesis. Prog. Polym. Sci. 2010, 35, 687-713. [CrossRef]

14. Smahel, J. Tissue reactions to breast implants coated with polyurethane. Plast. Reconstr. Surg. 1978, 61, 80-85. [CrossRef] [PubMed]

15. Socrates, G. Infrared and Raman Characteristic Group Frequencies: Tables and Charts, 3rd ed.; Wiley: Chichester, UK; New York, NY, USA, 2001; ISBN 0471852988.

16. Andreassen, E. Infrared and Raman spectroscopy of polypropylene. In Polypropylene; Karger-Kocsis, J., Ed.; Springer: Dordrecht, The Netherlands, 1999; pp. 320-328. ISBN 978-94-010-5899-5.

17. Geladi, P.; Kowalski, B.R. Partial least-squares regression: A tutorial. Anal. Chim. Acta 1986, 185, 1-17. [CrossRef] 